\title{
Optimising environmental monitoring for carbon dioxide sequestered offshore
}

\author{
Pierre William Cazenave, Marius Dewar*, Ricardo Torres, Jerry Blackford, Michael Bedington, \\ Yuri Artioli, Jorn Bruggeman \\ Plymouth Marine Laboratory (PML), Prospect Place, The Hoe, Plymouth PL1 3DH, United Kingdom
}

\section{A R T I C L E I N F O}

\section{Keywords:}

Carbon Capture and Storage

FVCOM

offshore geological storage

monitoring

marine

climate change

\begin{abstract}
A B S T R A C T
Carbon Capture and Storage (CCS) provides a mechanism by which CO2 can be removed from the atmosphere and stored in reservoirs. Regulations and stakeholder assurance require monitoring to show storage is robust. The marine environment is heterogeneous and dynamic, and baselines are extremely variable. Hence, distinguishing anomalous CO2 from natural variability is challenging. Monitoring schemes must be designed to identify releases early and with certainty, whilst being cost effective. A key question is how to deploy the smallest number of sensors to ensure effective monitoring?

We approached this problem through a 3D hydrodynamic model (FVCOM) coupled to a carbonate system. The unstructured grid resolution ranges from $0.5 \mathrm{~km}$ to $3 \mathrm{~m}$ and simulates seabed release scenarios ranging from $3 \mathrm{t}$ $\mathrm{d}-1$ to $300 \mathrm{t} \mathrm{d}-1$ using the Goldeneye complex as an exemplar test bed. This configuration allows us to characterise and analyse the fate of $\mathrm{CO} 2$ in the water column, with the spatial and temporal $\mathrm{CO} 2$ patterns shown to be affected by both tides and seasonal mixing/stratification.

A weighted greedy set algorithm is used to identify the positions within the model domain which yield the greatest combined coverage for the smallest number of sampling stations, further limited by selecting only a feasible number of sample sites. The weighted greedy set algorithm incorporates the effect of the variable grid spacing as well as the proximity of the sample locations to the Goldeneye complex. The weighted greedy set can identify releases sooner, with a stronger signal than a regular sampling approach.
\end{abstract}

\section{Introduction}

Carbon Capture and Storage (CCS) involves capturing CO2 from point source emitters and compressing and burying the $\mathrm{CO} 2$ in depleted oil and gas reservoirs and saline aquifers. The Intergovernmental Panel on Climate Change (IPCC) reports indicate CCS is an important strategy in reducing mitigation measure costs (Pachauri et al., 2014) if atmospheric CO2 emissions are to be reduced by the $80-95 \%$ by 2050 required to keep rising average global temperatures below $2^{\circ} \mathrm{C}$.

A large proportion of these potential storage formations lie in shelf seas near coastal communities. The world's shelf seas host an enormous amount of economic activity and maintain a complex ecosystem which has been shown to modulate the impacts of climate change through CO2 uptake (Artioli et al., 2014; Barange et al., 2011). Whilst properly engineered storage is not expected to leak, there is a regulatory requirement to assess risk and possible impact should $\mathrm{CO} 2$ be released in the water column. Field work in which realistic releases are investigated is difficult, expensive and risks harm to the environment. The use of numerical models provides a mechanism by which multiple scenarios can be assessed whilst minimising cost and environmental impacts (Blackford et al., 2008, 2013, 2020; Blackford and Gilbert, 2007; Greenwood et al., 2015; Hvidevold et al., 2015; Phelps et al., 2015).

$\mathrm{CO} 2$ dissolves readily in water, dissociating into bicarbonate and hydrogen ions. Increases in hydrogen ions decrease in situ $\mathrm{pH}$. Since rates of absorption of atmospheric $\mathrm{CO} 2$ into the ocean are increasing, any further changes in the oceanic carbonate system is particularly undesirable. The behaviour of the gaseous component of a $\mathrm{CO} 2$ release in high concentrations is as follows: the initially highly buoyant $\mathrm{CO} 2$ dissolves rapidly creating a slightly denser plume of water with a high $\mathrm{CO} 2$ concentration, which can sink in the immediate vicinity of the release at high release rates (Dewar et al., 2013; Dewar et al., 2013b). Subsequent dispersal of the $\mathrm{CO} 2$ is a function of the local

\footnotetext{
* Corresponding author.

E-mail address: made@pml.ac.uk (M. Dewar).
} 
hydrodynamics, principally the surface wind, tidal mixing, diffusion, turbulence and residual circulation.

Existing modelling and in situ work on the dispersal of $\mathrm{CO} 2$ in shelf sea settings is relatively limited. Blackford (2013) investigated the dispersal of $\mathrm{CO} 2$ in tidally dominated small coastal model domains in depths of up to $75 \mathrm{~m}$ and found that releases emanating from the seabed reach the sea surface over periods of order a few days. The Quantifying and Monitoring Potential Ecosystem Impacts of Geological Carbon Storage (QICS) project in situ experiment was conducted in very shallow water $(<10 \mathrm{~m})$. At these water depths, the $\mathrm{CO} 2$ bubbles released from the seabed did not have sufficient time to dissolve into the water column and thus made their way to the surface in very short periods of time $(; 1$ minute) (Sellami et al., 2015). The QICS project was situated at the edge of a Scottish loch where horizontal currents were very limited, especially compared with currents found on shelf seas. Dewar et al. (Dewar et al., 2013, 2015; Dewar et al., 2013b) have shown that rate at which CO2 makes its way from the seabed to the sea surface is strongly dependent on the current flow. The rapid dilution of the $\mathrm{CO} 2$ means that whilst relatively large volumes might be lost from a CCS site, the impact is relatively short-lived following cessation of $\mathrm{CO} 2$ release. The spatial impact has been shown to be felt only over a region immediately adjacent to the release site of order metres to kilometres, depending on the release rate (Blackford et al., 2008, 2020; Chen et al., 2005; Dewar et al., 2013; Dewar et al., 2013b). Additionally, the rate of transfer of CO2 across the air-sea interface is dependent on the wind speed (Blomquist et al., 2017; Nightingale et al., 2000). Oleynik et al., (2020), Hvidevold et al. (2015) and Greenwood et al. (2015) have investigated optimal approaches to monitoring for leakage based on the number of instruments available and the sensitivity of those instruments to changes in a number of parameters (particle density, $\mathrm{CO} 2$ concentration) and the number of potential release sites. Hvidevold et al. (2015) approached the problem of optimal sensor distribution on the seabed from the basis of the probability of a release occurring within a defined region, based on probable pathways to release from a site in the North Sea, where locations in the vicinity of wells and faults are assumed to have a higher probability of a release occurring. Given this network of potential release sites, a release footprint is computed based on an $800 \mathrm{~m}$ circulation model's tidal ellipse and an assumed CO2 dispersion, yielding an efficient way of producing $\mathrm{CO} 2$ distributions across a model domain, albeit with reduced dynamics compared with a full hydrodynamic model simulation. Using these release probability ellipses, a genetic algorithm is used to place sensors within the domain. The results indicate that compared with a uniform grid, the probability of detecting a release increases from $12 \%$ to $21 \%$ for 9 sensors and from $22 \%$ to $32 \%$ for 16 . In essence, the same probability of detection can be achieved with the genetic algorithm placement with 7 fewer sensors.

Greenwood et al. (2015) expanded upon the work of Hvidevold et al. (2015) by removing the requirement for a pre-defined set of potential release locations. Using a Lagrangian particle tracking approach to simulating $\mathrm{CO} 2$ transport within a depth-averaged circulation model, the probability of a release being observed within the model domain was computed independent of where the release was. Using the probability maps calculated from the particle tracking, a set of sensor locations could be created which could maximise the probability of identifying a leak without knowing where in the domain that release occurred. However, both methods assumed that all possible leaks would present the same footprint (Oleynik et al., 2020).

Oleynik et al., (2020) re-developed the work of Hvidevold et al. (2015) through a classical set cover problem, using established approximation algorithms. This allowed different cost functions to be minimized, such as the number of sensors, the sensor cost (including maintenance), and the probability of a leak at specific locations. The work also uses more realistic footprints taken from low resolution numerical models $(800 \mathrm{~m}$ ), with the simulated release resolved through an advection-diffusion system.

Oleynik et al., (2020), Hvidevold et al. (2015) and Greenwood et al.
(2015) have based their analysis on the assumption that the advection of $\mathrm{CO} 2$ in a marine environment can be approximated by a passive tracer (Hvidevold et al., 2015; Oleynik et al., 2020) and Lagrangian particles (Greenwood et al., 2015). Here, we extend the existing body of work to model the $\mathrm{CO} 2$ explicitly within a geochemical model and 3D simulation for a range of release rates within a tidally dominated shelf sea.

A Finite Volume Community Ocean Model (FVCOM) of the northwest European continental shelf provides inputs for a high resolution ( $500 \mathrm{~m}$ to $3 \mathrm{~m}$ ) region in the vicinity of the Goldeneye potential storage complex in the Northern North Sea. The high-resolution domain is used to investigate the behaviour of a range of $\mathrm{CO} 2$ release scenarios. Coupling a geochemical model to FVCOM means we simulate the evolution of the $\mathrm{CO} 2$ concentration in the water column. Results from (Dewar et al., 2013; Dewar et al., 2013b) showed that for bubbly plumes at similar rates and depths in the North Sea, most of the $\mathrm{CO} 2$ gas dissolved within the first 3 meters. Therefore, with a vertical resolution of over 4 meters, the model can assume that the $\mathrm{CO} 2$ flux from the seabed fully dissolves within the bottom model layer. It is considered that the increase in seawater density from the dissolved $\mathrm{CO} 2$ is very small and is highest at the source where the concentration is greatest. Therefore, any dissolution beyond the bottom model layer would likely drop to this layer at the release point. The results are analysed in terms of how to design a monitoring strategy to maximise the likelihood of timely leakage detection given those scenarios. We focus our efforts on the spatial monitoring in the vicinity of an identified potential release location, working on the assumption that the unlikely event of a release has a probability which increases with proximity to existing wells and faults (Hvidevold et al., 2015).

\section{Methods}

This section outlines the two principal aspects of this work: the design and implementation of the hydrodynamic model and the transport of $\mathrm{CO} 2$ within it; and the approach used to design an optimal monitoring network.

\subsection{Hydrodynamic Modelling Configuration}

The Finite Volume Community Ocean Model (FVCOM) is a prognostic, unstructured-grid, finite- volume, free-surface, 3D primitive equation coastal ocean circulation model (Chen et al., 2003). FVCOM solves the 3D momentum, continuity, temperature, salinity and density equations by computing fluxes between unstructured triangular elements. Vertical turbulent mixing is modelled with the Mellor-Yamada formulation (Mellor and Yamada, 1982) whilst horizontal mixing is parameterised through the Smagorinsky scheme (Smagorinsky, 1963). The vertical grid in FVCOM is described in terrain following (sigma) coordinates where shallower areas resolve vertical structure with finer detail.

FVCOM has been widely used in shelf and coastal domains for a range of problems where a strong need exists to resolve varying horizontal scales, including: modelling of temperature and salinity stratification (Chen et al., 2007; Ge et al., 2013; Huang, 2011; Yang and Khangaonkar, 2008; Zheng and Weisberg, 2012); impacts from marine renewable energy devices (Cazenave et al., 2016; De Dominicis et al., 2017; Li et al., 2020); tracer evolution in complex estuaries (Torres and Uncles, 2011); tracking Harmful Algal Blooms (HABs) (Aleynik et al., 2016); the relationship between hydrodynamics and pursuit diving bird behaviour (Waggitt et al., 2016a,b, 2018); the behaviour of sequestered CO2 release plumes in coastal seas (Blackford et al., 2013); and tracking the dispersal of lice (Adams et al., 2012, 2014). FVCOM has been coupled with the European Regional Seas Ecosystem Model (ERSEM) biogeochemical model (Butenschön et al., 2016) through the Framework for Aquatic Biogeochemical Models (FABM) coupler (Bruggeman and Bolding, 2014) to provide a full carbonate system (Blackford et al., 2004; Blackford and Gilbert, 2007). 


\subsection{Configuration}

The release scenarios are simulated in a nested FVCOM configuration. A large domain describing the north-west European continental shelf (figure 1a) is used to provide boundary conditions for the smaller domain (figure 1b) surrounding the release complex.

The grid resolution in the large domain is based on a size function calculated using the curvature of the coastline and the water depth, ensuring that parts of the domain with complex topography are well resolved so the local hydrodynamics are accurately reproduced (Legrand et al., 2006, 2007). The bathymetry used is the European Marine Observation and Data Network (EMODnet) Digital Terrain Model (DTM) (http://www.emodnet-hydrography.eu) interpolated onto the model grid. The model has 25 vertical levels in a hybrid configuration of quadratic and uniform thickness terrain sigma coordinates with a cut-off depth of $50 \mathrm{~m}$ for the change from quadratic (deeper) and uniform (shallower). This approach minimises instabilities in shallow regions where a quadratic distribution can yield very thin vertical layers close to the seabed and sea surface.

Temperature, salinity, currents and tidal elevation are prescribed at the model open boundaries using data representing the year 2015. Sea surface elevation and current forcing at the open boundaries of the larger domain are generated from 11 tidal constituents (M2, S2, N2, K2, K1, O1, P1, Q1, M4, MS4, MN4) calculated from tides-only FVCOM output of the grid in figure 1a. Depth-resolved temperature, salinity and non-tidal velocity inputs are sourced from the $1 / 15 \times 1 / 10^{\circ}$ north-west European continental shelf operational Forecast Ocean Assimilation Model (FOAM) daily mean data retrieved from Copernicus - Marine environment monitoring service (CMEMS) interpolated onto the FVCOM vertical grid at the open boundary nodes.

Surface forcing (wind, heating, precipitation) is generated from a nested Weather Research and Forecasting (WRF) model (Michalakes et al., 2001; Skamarock et al., 2008) configured for the UK shelf (figure 2). WRF is forced with National Center for Atmospheric Research (NCAR) FNL Operation Global Reanalysis $1^{\circ}$ 6-hourly data (National Centers for Environmental Prediction / National Weather Service / NOAA / U.S. Department of Commerce, 2000) and the $1 / 2^{\circ}$ daily Real time global (RTG) Sea surface temperature (SST) product (Reynolds, 1988). WRF is run with a 6 hour spin up for each 24 hour model run; each modelled day is reinitialised to the NCAR FNL and RTG SST values

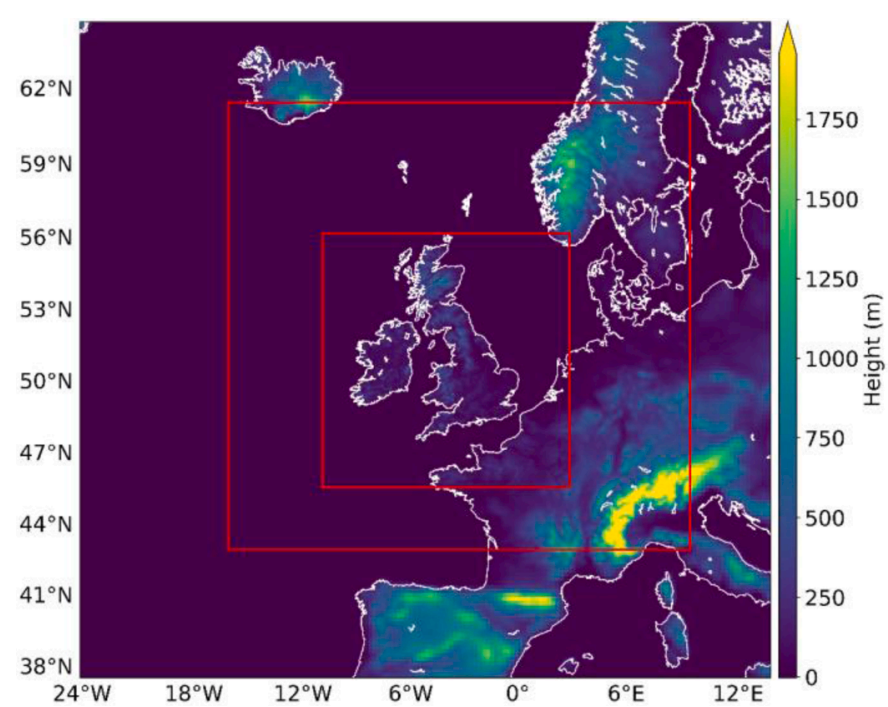

Figure 2. WRF model domain with the nested domains (red lines) used to generate surface forcing for FVCOM. Resolution varies from $20 \mathrm{~km}$ in the largest grid, to $6.67 \mathrm{~km}$ and $2.2 \mathrm{~km}$ in the two nests. Boundary forcing comes from the National Centers for Environmental Prediction (NCEP) FNL Operational Global Reanalysis $1^{\circ}$ data from NCAR.

to prevent model drift. The WRF outputs are saved every 3 hours and converted to FVCOM surface forcing using the COARE3.0 bulk air-sea flux parameterisations (Fairall et al., 2003). Sea surface temperature is nudged to remotely sensed SST in FVCOM (Chen, 2013) from the Group for High Resolution Sea Surface Temperature (GHRSST) Level 4 G1SST Global Foundation Sea Surface Temperature Analysis daily data (Chao et al., 2009).

Inputs for the nested domain (figure 1b) are taken directly from the larger domain. The release site is shown as a red star in figure1b. The finer domain has element side lengths ranging from $0.5 \mathrm{~km}$ at the boundary to approximately $3 \mathrm{~m}$ at the $\mathrm{CO} 2$ release site, at a depth of $116.8 \mathrm{~m}$ and 25 vertical levels providing a vertical resolution of $4.67 \mathrm{~m}$.
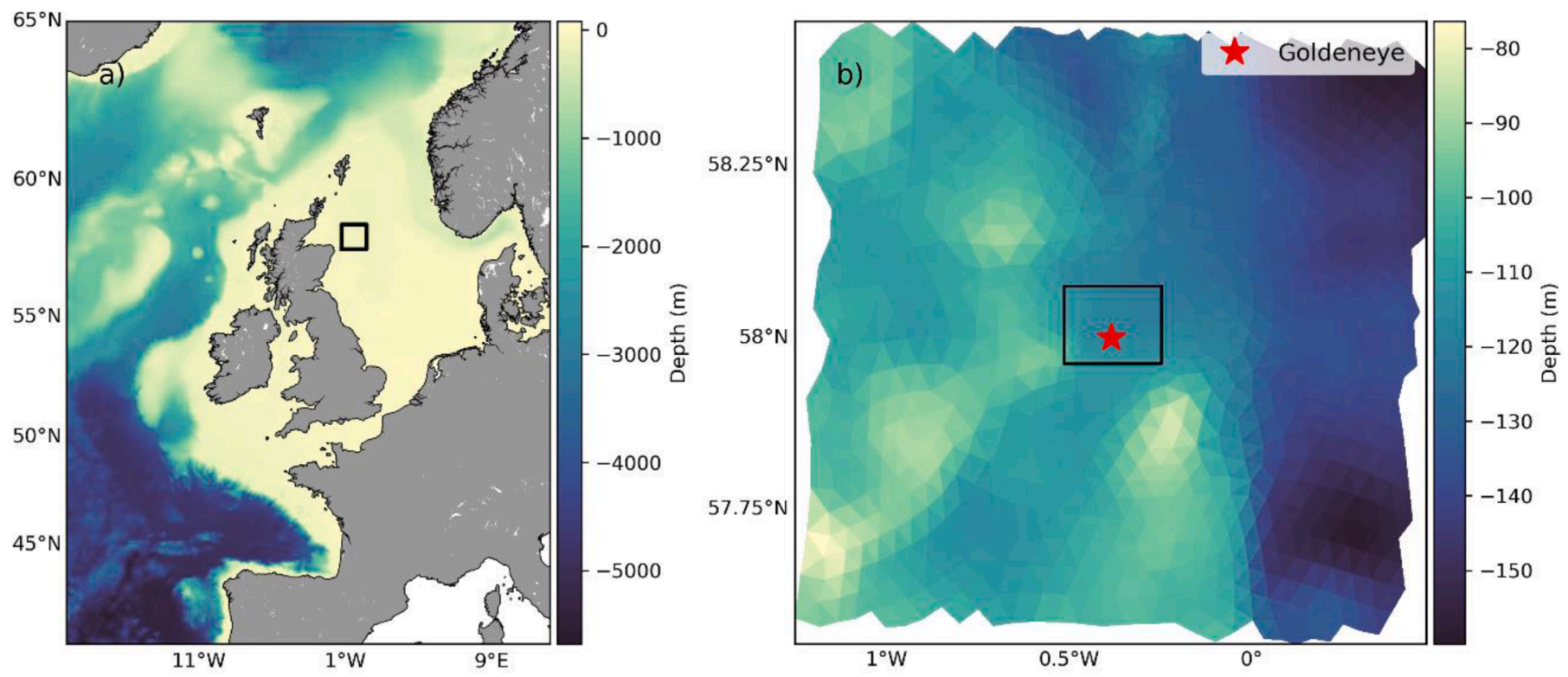

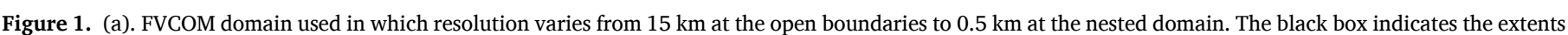

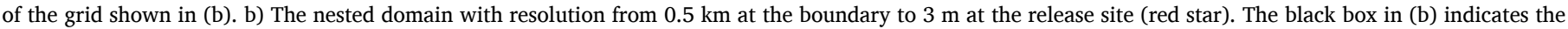
extent of the Goldeneye complex. 


\subsection{Hydrodynamic scenarios}

The model is run for two times of year: a fully mixed winter (January) and a stratified summer (June), both set to initiate with spring tides with a 2 week simulation to cover the spring-neap tidal cycle. These scenarios therefore provide the largest range of potential conditions from highly energetic in winter with spring tides to minimally so in summer under neaps. Modelled tidal currents within the domain are up to $1.6 \mathrm{~m} \mathrm{~s}-1$ with WRF $10 \mathrm{~m}$ wind speeds of up to $28 \mathrm{~m} \mathrm{~s}-1$. Initial conditions for the nested domain (figure $1 \mathrm{~b}$ ) are taken from the state of the model in figure $1 \mathrm{a}$ and interpolated to the nested grid removing the requirement for a long spin up time.

\subsection{CO2 release modelling}

The carbonate system was introduced to ERSEM in Blackford and Burkill (2002) and uses the HALTAFALL speciation code from Ingri et al. (1967) to calculate all carbonate system variables. Total alkalinity is computed from values of dissolved inorganic carbon (DIC), total alkalinity (TA) and total boron (Blackford and Gilbert, 2007; Butenschön et al., 2016). Total alkalinity in ERSEM can be calculated in a number of ways (diagnostically, semi-diagnostically or prognostically) (Butenschön et al., 2016). Total boron is a simple linear regression of salinity. More details on the carbonate system in ERSEM can be found in Artioli et al. (2012) and Butenschön et al. (2016). The model configuration employed here sets a constant initial total DIC concentration of $2130 \mathrm{mmolC} / \mathrm{m} 3$. Atmospheric CO2 concentration is set at $390 \mathrm{ppm}$ across the model domain and the air-sea flux of $\mathrm{CO} 2$ uses the Nightingale et al. (2000) formulation. TA is calculated from the modelled salinity and temperature values yielding a spatio-temporally varying TA field.

The CO2 flux is modelled as a direct injection into the bottom layer in the vertical model grid at a single model node representing $8.7 \mathrm{~m} 2$ of the seabed or $39.0 \mathrm{~m} 3$ to $40.0 \mathrm{~m} 3$ (depending on tide) of the water column. Table 1 shows the three release rates used in the model. These scenario rates cover releases which might occur via an abandoned well bore or geological discontinuity, at the lower end of detectability (Blackford et al., 2020). Scenarios that represent larger rates, a well blowout for example, are highly impacted by local multiphase hydrodynamic jet and bubble plume dynamics (Dasanayaka and Yapa, 2009; Wang et al., 2018). However, the detectability of such events is very high (sensors in the injection mechanism and around injection zone), and could potentially be rectified within hours (Manceau et al., 2014). As such, the scenarios are designed to cover the other plausible range of events, without considering the likelihood of any given event (Paulley et al., 2013). The release rate increases from zero to the prescribed rate over a period of 1 day following a hyperbolic tangent after which the rate remains constant for the remainder of the model run (two weeks). It is important to note that there is a very low probability of $\mathrm{CO} 2$ release from a reservoir and that the development of monitoring strategies explored in this manuscript is for assurance of no release.

The approach we use is similar to one used for identifying optimal or evaluating existing sampling strategies for large ocean basins (Fu et al., 2011; She et al., 2014). This method investigates the monitoring in terms of the spatial distribution of sampling points required to capture some threshold of the signal for which we are monitoring allowing for the design of an optimal monitoring network, which may include realistic constraints (e.g. the number of sensors). Identifying monitoring

Table 1

$\mathrm{CO} 2$ release scenarios

\begin{tabular}{ll}
\hline $\mathrm{CO} 2(\mathrm{t} \mathrm{d}-1)$ & $\mathrm{CO} 2(\mathrm{mmol} \mathrm{m}-2 \mathrm{~s}-1)$ \\
3 & 91.141 \\
30 & 911.41 \\
300 & 9114.1 \\
\hline
\end{tabular}

strategies which recognise this limitation can have significant associated cost savings compared with less optimal or unconstrained sampling designs.

The optimal spatial distribution of sampling locations of the FVCOM grid uses a weighted greedy set algorithm (Young, 2008) with an initially uniform sampling grid (figure $3 \mathrm{a}$ ). With a collection of sets $\mathrm{S}$ within a universe $U$, the set cover $C \subseteq S$ has a union $U$. The greedy set algorithm will identify the set cover with minimum cardinality. This can be further modified by weighting each set $s \in S$ by a weight $w \geq 0$ which is used to find the set cover $C$ with the minimum total weight in all the sets $\sum_{-}(\mathrm{C} \in \mathrm{S})$. In this application, given the unstructured grid in FVCOM, the area associated with each node is used to generate the weights. In other words, we generate a number of coverages which contain a varying number of model nodes for each position in the initially uniform sampling grid. The weighted greedy set algorithm takes those individual coverages and finds the minimum number required to maximise the total coverage of the domain.

To generate the sets $\mathrm{S}$, a reference time series of the anomaly signal, in this case $\mathrm{pH}$, is extracted from the model grid at each location in the uniform sampling grid (figure $3 a$ ). Each of these reference time series is compared with the remaining time series within the model grid and the correlation coefficient calculated, yielding a coefficient for each uniform sampling location (figure $3 \mathrm{~b}$ ). The correlation coefficients at each uniform sampling location are filtered based on a threshold value and the locations which pass the filtering are a set $s \in S$ (figure $3 c$ ). This yields a coverage for each node in the uniform sampling grid (figure $3 \mathrm{~d}$ ). The universe $U$ is the unique list of nodes in all the sets $S$. For each set $s \in S$, the weighting is created based on the area each FVCOM node represents (a necessary prerequisite of working with an unstructured model grid) as well as the distance from the storage complex. Were the model outputs regularly gridded, a simpler greedy set algorithm could be employed instead (Young, 2008). However, the weighted greedy set algorithm also means that other parameters can be used to preferentially select specific regions. The weighted greedy set algorithm minimises the number of sets (weighted as above) required to maximise coverage of the domain (figure $3 \mathrm{e}$ ). The number of locations is artificially restricted to mimic a finite number of in situ sensors to yield an optimal coverage (figure $3 \mathrm{f}$ ).

\section{Results}

\subsection{CO2 Release propagation}

The following section explores and quantifies the fate of the $\mathrm{CO} 2$ as it is advected within the model domain. As dissolved CO2 is acidic, it causes a reduction in the $\mathrm{pH}$ of the waters. Figure 4 shows the volumes and seabed areas (in the first vertical layer) affected by a range of changes in $\mathrm{pH}$ relative to a model run with no release.

The thresholds of change in $\mathrm{pH}$ relative to a run with no release range from 1.0 to 0.001 in increments of an order of magnitude. These thresholds include those which have impacts on the biology in the vicinity of the release ( 0.1 and 1.0$)$ and ones at the sensitivity limits of currently available $\mathrm{pH}$ sensors (0.01). The modelling work here extends the lower sensitivity limit in anticipation of improvements in sensor technology. For all scenarios tested, changes exceeding 0.001 and 0.01 are evident in the model results. At a threshold of 0.1 , the smallest release $(3 \mathrm{td}-1)$ is not evident in either of the simulations (mixed or stratified) or in the metric (area or volume). Similarly, at a threshold of 1.0 , the two smallest release rates $(3 \mathrm{td}-1$ and $30 \mathrm{td}-1)$ are not evident.

Under stratified conditions, the affected areas and volumes of larger $\mathrm{pH}$ changes are between $30 \%-50 \%$ of those for a fully mixed water column. Although both simulations are at a similar spring-neap tidal phase, the mean horizontal velocity at the release site, both at the seabed, and higher in the water column, is found to be $20 \%$ higher under stratified conditions than in the fully mixed water column. This greater horizontal advection and diffusion at the seabed during the summer months, dilutes the concentration, yielding smaller areas and volumes of 


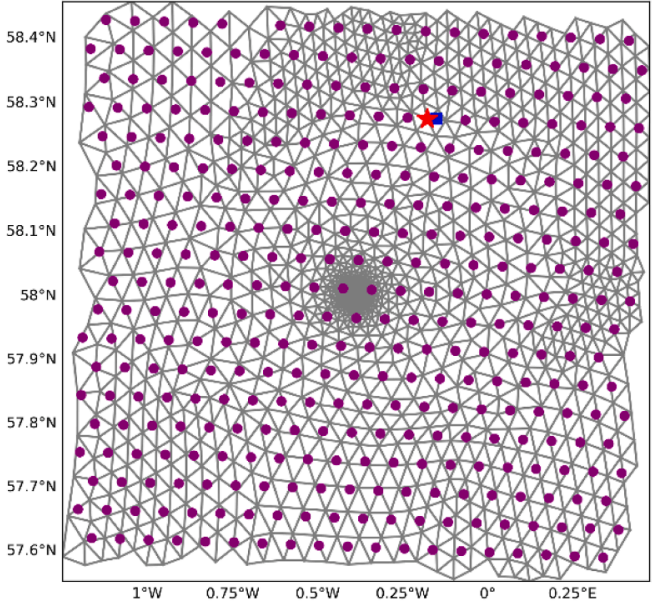

(a) Regular sampling (dots) with model node (star) for the adjacent sample (square).

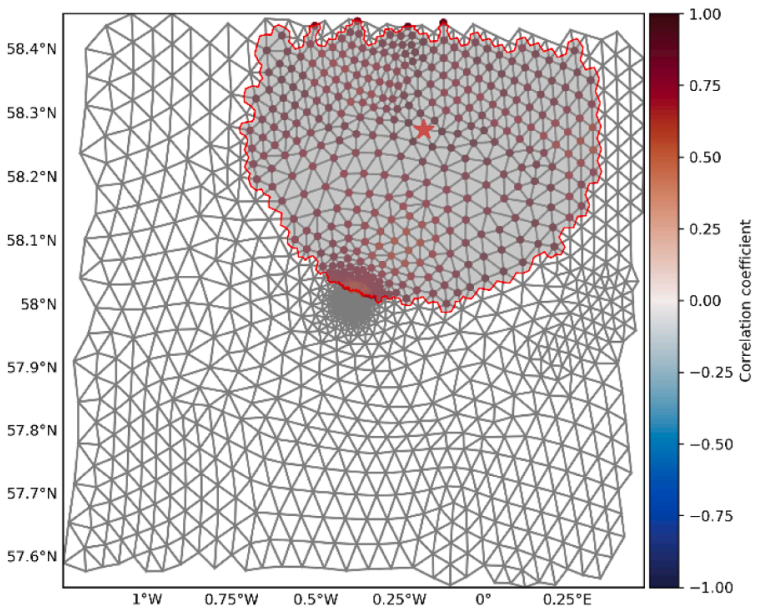

(c) Region of similarity defined based on a threshold correlation drop.

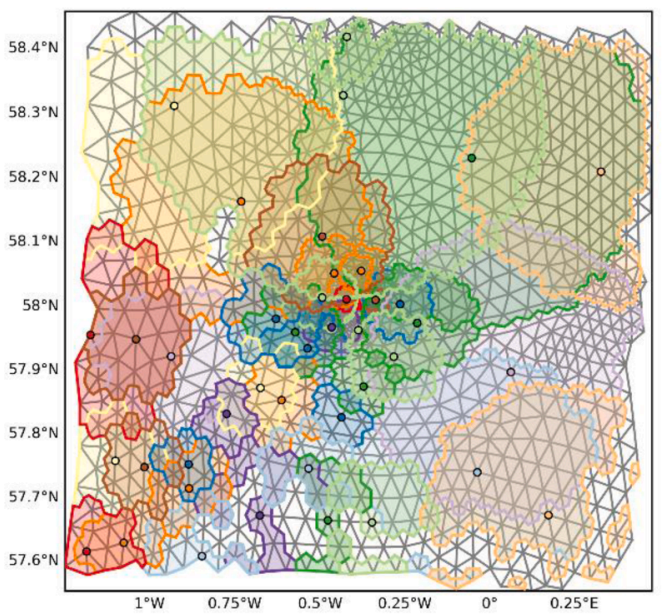

(e) The results of the weighted greedy set algorithm applied to the regions for all the locations in the initial uniform grid. The colours in this figure serve only to clarify different regions identified by the analysis. Similar colours do not imply any link between regions

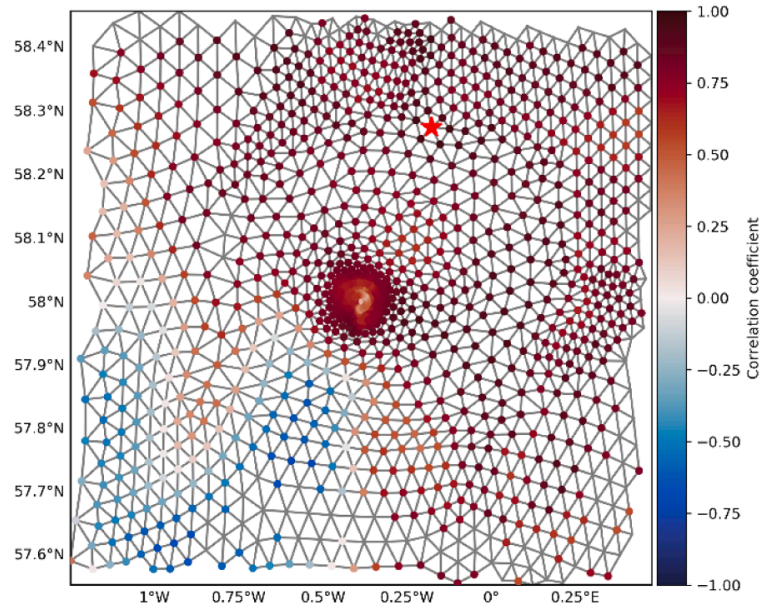

(b) Correlation coefficient between time series at each model grid point and the starred location.

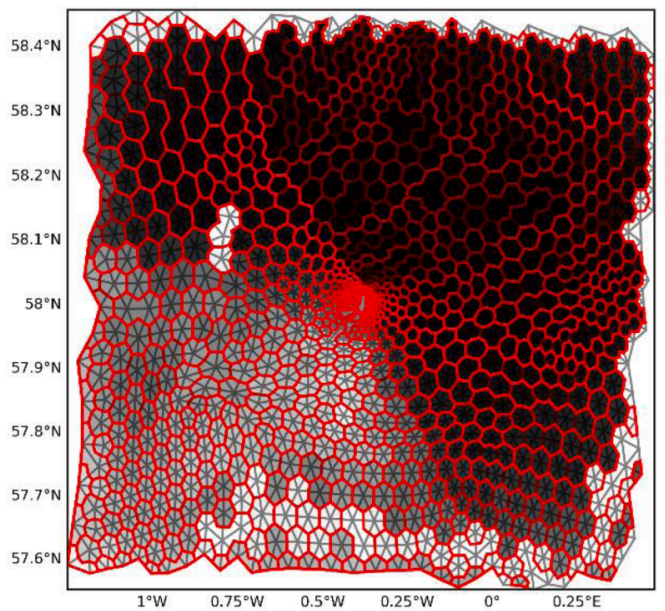

(d) The regions of similarity for all locations in the grid. A darker shading indicates a larger number of regions are identified for part of the domain.

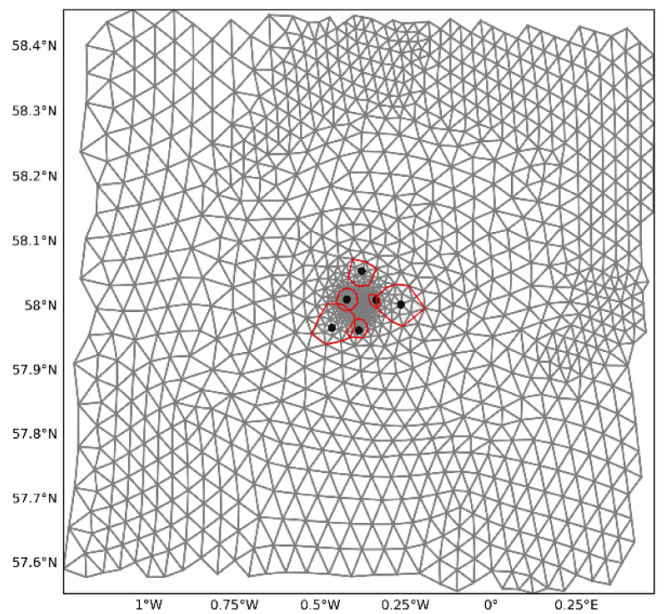

(f) Coverage of similar water properties for the given domain for a limited number of sites.

Figure 3. The process by which the weighted greedy set algorithm selects the sampling locations from FVCOM output of pH. 

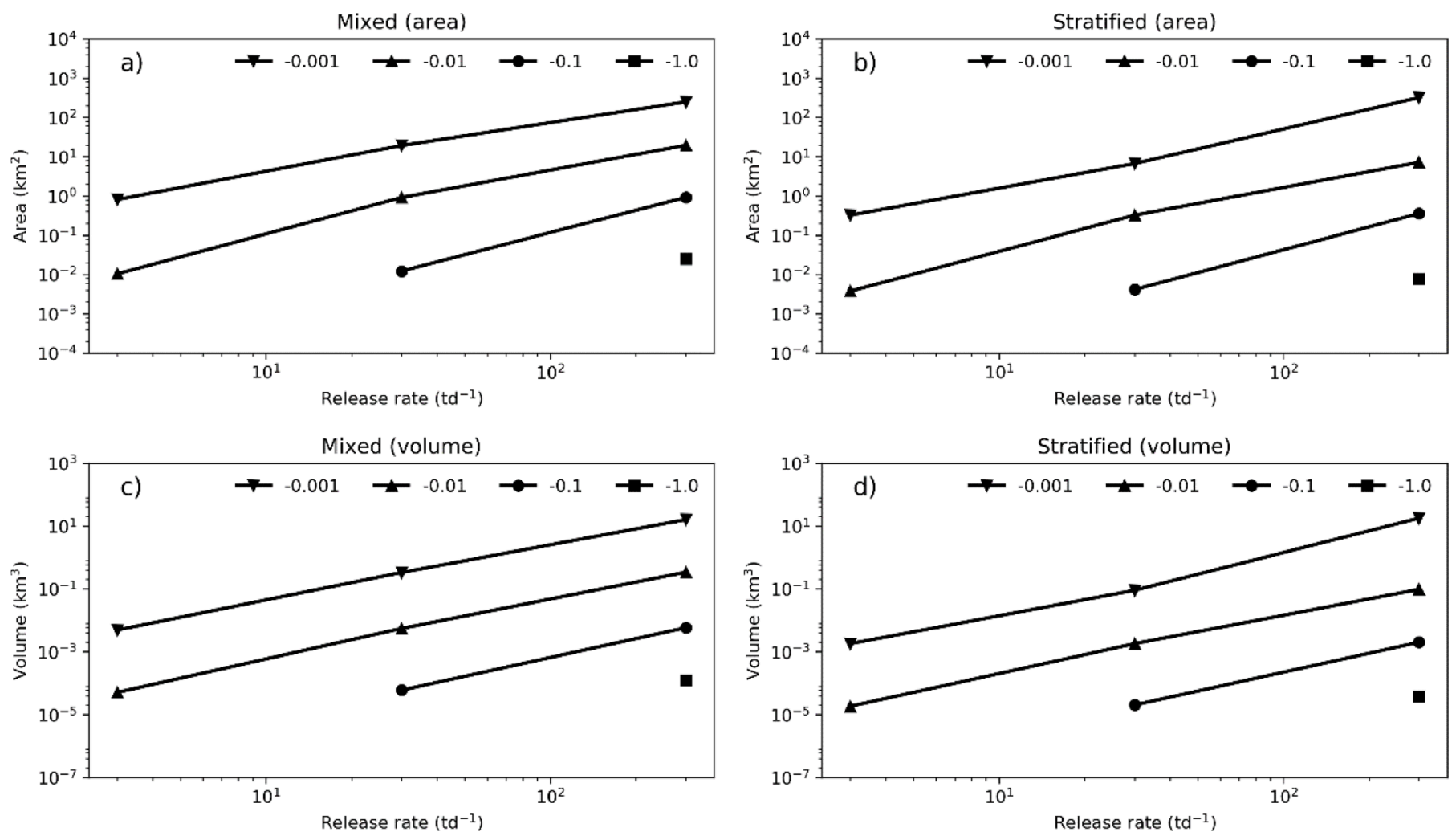

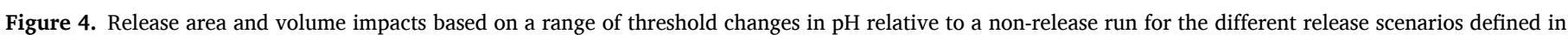
table 1.

a higher $\mathrm{CO} 2$ concentration and thus a lower $\mathrm{pH}$, but in turn providing a larger area of the smaller $\mathrm{pH}$ changes as shown in Figure $4 \mathrm{a}-4 \mathrm{~d}$. Areas affected with a threshold $\mathrm{pH}$ change of -0.01 range from $0.00377 \mathrm{~km} 2$ for a $3.0 \mathrm{t} \mathrm{d}-1$ release under stratified conditions, and up to $19.1 \mathrm{~km} 2$ for a $300 \mathrm{t} \mathrm{d}-1$ scenario in a fully mixed water column as shown in Figure $4 \mathrm{a}$ and $4 \mathrm{~b}$.

Analysis of the modelled velocity field in the region indicates that the principal tidal axis is oriented $170^{\circ}$, with flood and ebb directions of $20^{\circ}$ and $112^{\circ}$, respectively. Depth-averaged speeds for flood and ebb tides are $0.19 \mathrm{~m} \mathrm{~s}-1$ and $0.21 \mathrm{~m} \mathrm{~s}-1$, respectively. Based on this information, the analysis of the maximum release time-integrated (cumulative) extent (figure 5) shows that for the release rates in table 1 and a threshold $\mathrm{pH}$ of 0.01 , the spatial extents are confined to within $77 \mathrm{~m}$, $829 \mathrm{~m}$, and $3747 \mathrm{~m}$ of the release point, respectively. The full plume length is reached within a matter of hours, and the full impact areas and volumes settle to a quasi-steady state within the first major tidal cycles with little impact from the spring-neap cycle recorded. However, differences in the distribution manifest themselves in the fully mixed and stratified scenarios through differences in the horizontal advection, with the former showing greater anisotropy in the horizontal distribution compared with the latter.

The progression of the release impact in the vertical is shown in figure 6. For each release scenario in table 1 for the $0.01 \mathrm{pH}$ drop threshold, the minimum depth within the model domain is plotted for each time point for the fully mixed and stratified model conditions. In addition to the depth, the mixed layer depth is calculated and plotted for the position at which the threshold is exceeded.

The smallest release rate $(3 \mathrm{td}-1)$ shows that the release impact is essentially confined to the seabed (the depth at the release location is $116.8 \mathrm{~m}$ ) in both the fully mixed and stratified scenarios. As the release rates increase, the $\mathrm{CO} 2$ plume penetrates higher in the water column. For the $300 \mathrm{td}-1$ release, the threshold is breached briefly in the surface model element (evident as the tidal signal in figure 6e).

The release through the water column follows the hyperbolic release rate over a day, with an initially slow increase followed by acceleration into the upper water column for the fully mixed conditions (left column in figure 6). Following the initial release, gradients in $\mathrm{pH}$ decrease and the release is confined to the lower water column. In addition to the ramping up of the release over a day, the initial vertical migration corresponds to a period of vertical velocity excursions of $2 \mathrm{~cm} \mathrm{~s}-1$ to 4 $\mathrm{cm} \mathrm{s}-1$ (compared with background values of $<0.75 \mathrm{~cm} \mathrm{~s}-1$ ). At the highest release rate $(300 \mathrm{td}-1)$, the release signature reaches the sea surface at a peak during the initial release in winter (fully mixed waters). The propagation of the $\mathrm{CO} 2$ into the upper water column coincides with a deepening of the mixed layer (defined as the depth at which the density at depth is greater than the surface density by at least $0.03 \mathrm{~kg}$ $\mathrm{m}-3$ ) (red dotted lines in figure 6). The highest penetration into the water column occurs when the threshold $\mathrm{pH}$ is breached close to the release. As the tides advect the $\mathrm{CO} 2$ away from the release, the $\mathrm{CO} 2$ is diluted in the water, reducing the drop in $\mathrm{pH}$ due to lower $\mathrm{CO} 2$ concentrations.

The timing of the height at which the threshold $\mathrm{pH}$ is breached in figure 6 is primarily controlled by the flood tide. The effect of the ebbing tide on the dynamics of the plume effect on $\mathrm{pH}$ in figure 6e, for example, is minimal, with the majority of the vertical penetration of the $\mathrm{CO} 2$ plume into the water column occurring on the flood tide. The vertical extent of the plume is also governed by the flood tide velocity: only as the velocity falls does the plume height increase due to the lack of advection of the $\mathrm{CO} 2$ away from the release site allowing $\mathrm{CO} 2$ concentration to accumulate, pushing the extent of the acidification upwards (see figure 6e around 2015-01-05, for example).

The stratified water column results (right column in figure 6) show that, for all release rates, the progression of the release into the upper reaches of the water column is effectively prevented. Comparison of the mixed layer depth in the generally fully mixed and stratified scenarios shows that the latter has a shallower mixed layer which keeps the released $\mathrm{CO} 2$ in the lower water column.

Figure 7 shows the dynamics of the $300 \mathrm{td}-1 \mathrm{CO} 2$ plume and how its 


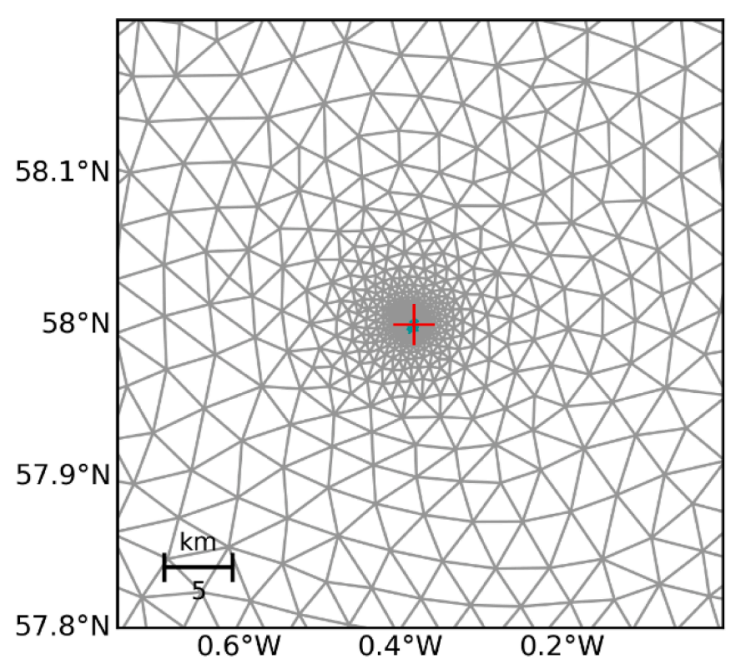

(a) $3 \mathrm{td}^{-1} \mathrm{CO}_{2}$ release

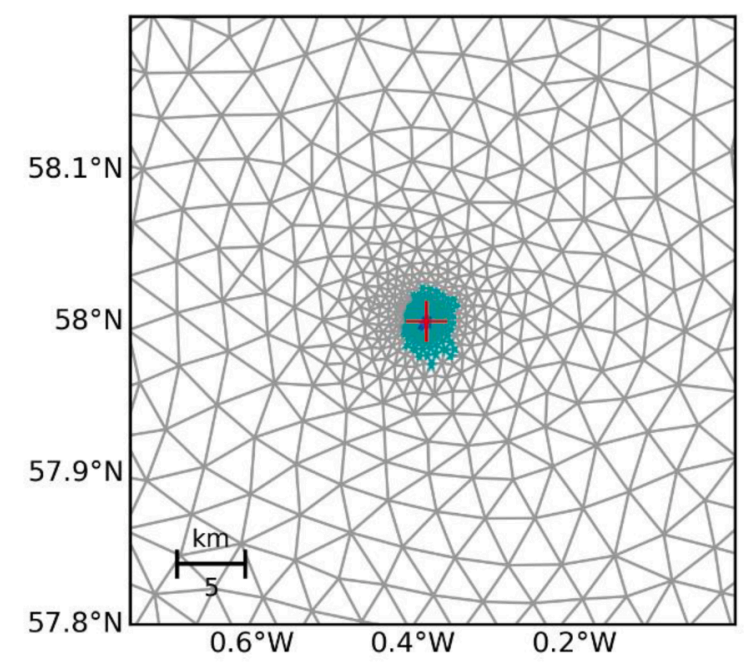

(c) $30 \mathrm{t} \mathrm{d}^{-1} \mathrm{CO}_{2}$ release

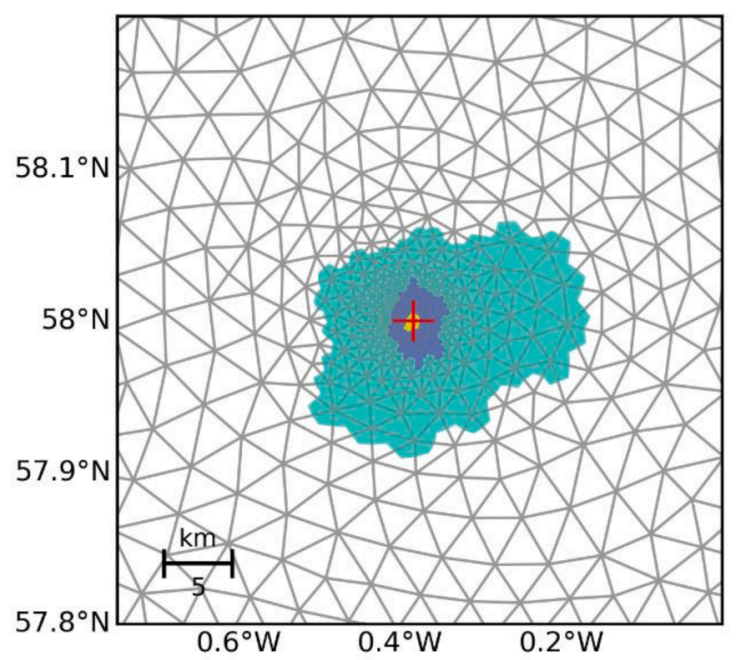

(e) $300 \mathrm{t} \mathrm{d}^{-1} \mathrm{CO}_{2}$ release

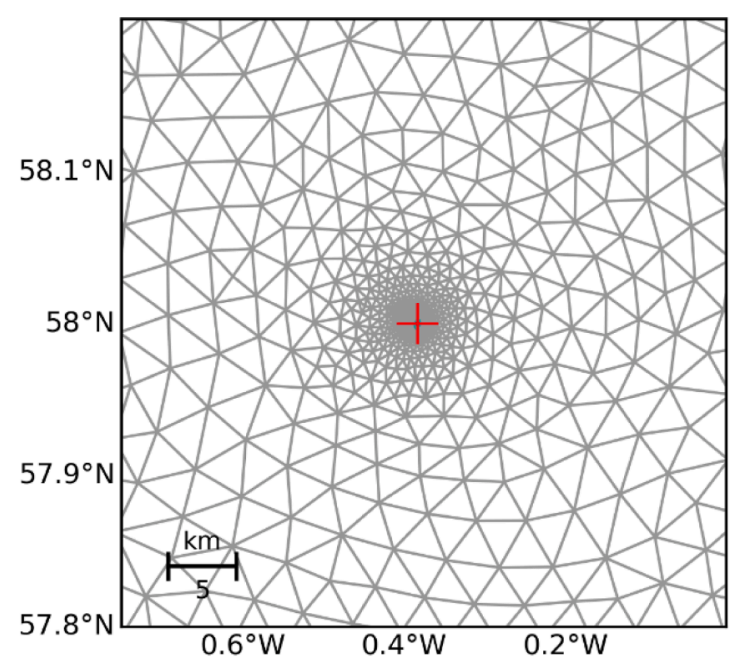

(b) $3 \mathrm{t} \mathrm{d}^{-1} \mathrm{CO}_{2}$ release

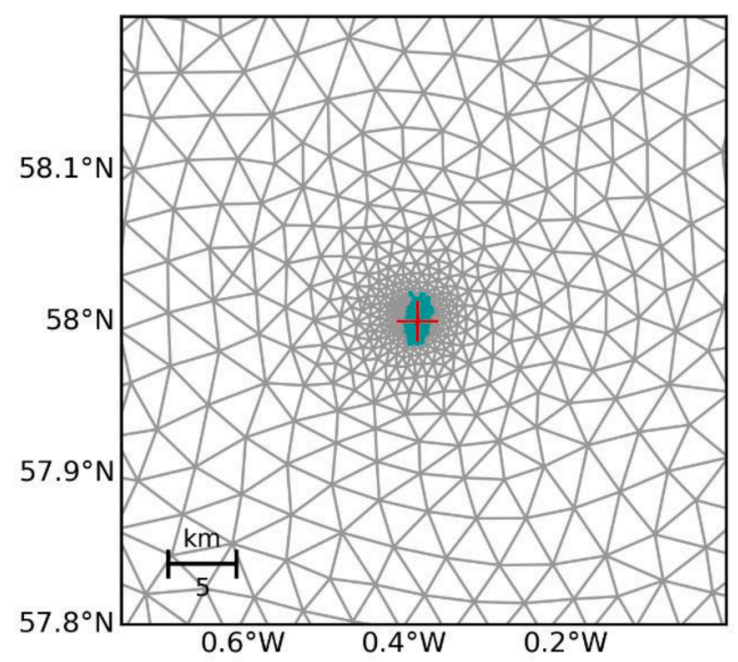

(d) $30 \mathrm{t} \mathrm{d}^{-1} \mathrm{CO}_{2}$ release

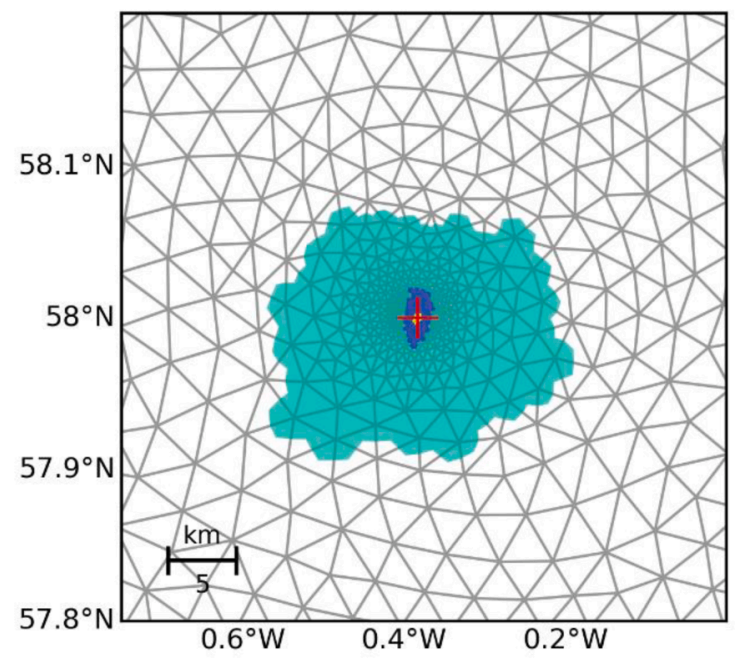

(f) $300 \mathrm{t} \mathrm{d}^{-1} \mathrm{CO}_{2}$ release

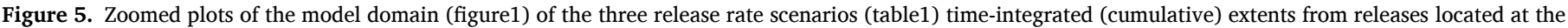

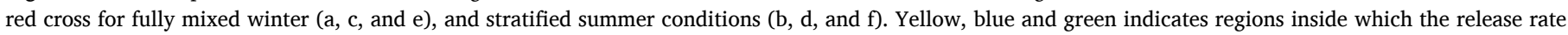

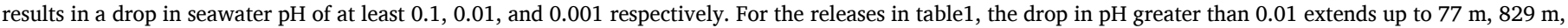
and $3747 \mathrm{~m}$ from the release, respectively. 


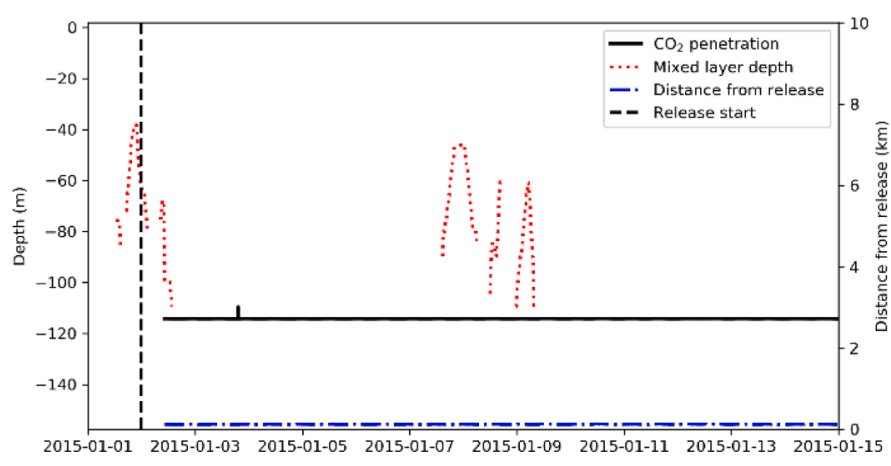

(a) $3 \mathrm{td}^{-1} \mathrm{CO}_{2}$ release

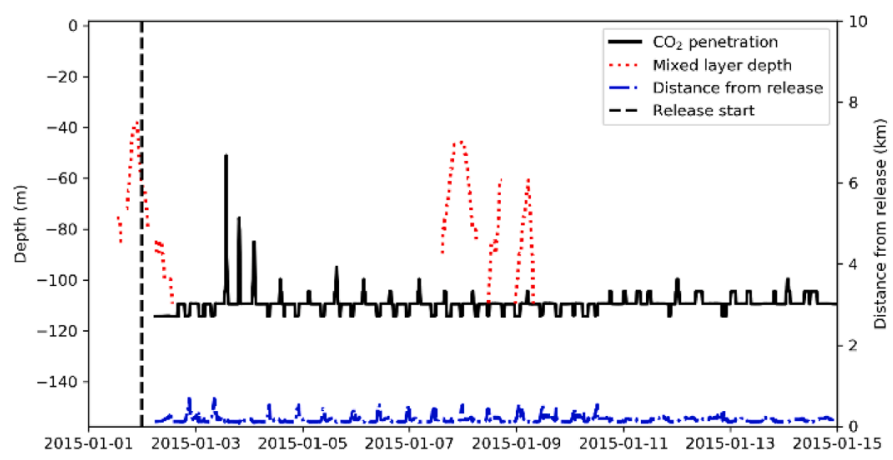

(c) $30 \mathrm{t} \mathrm{d}^{-1} \mathrm{CO}_{2}$ release

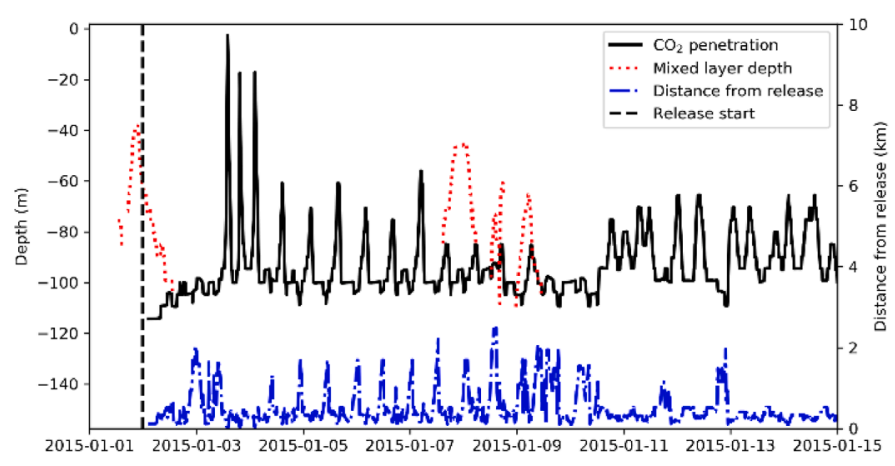

(e) $300 \mathrm{t} \mathrm{d}^{-1} \mathrm{CO}_{2}$ release

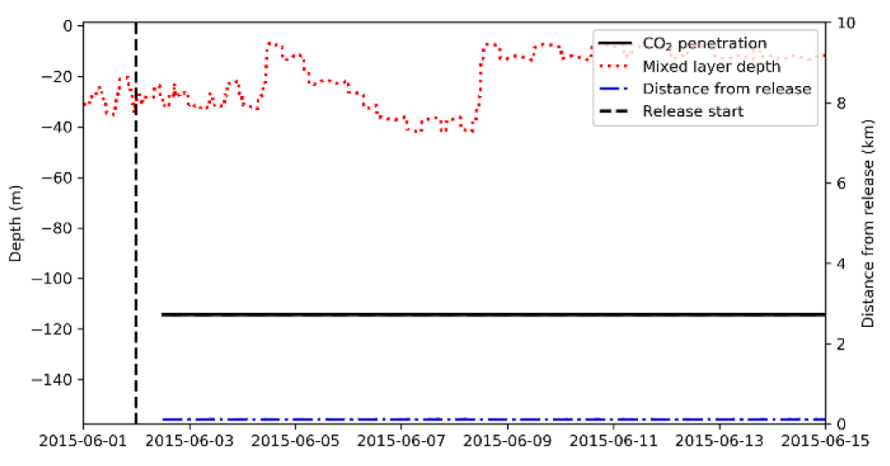

(b) $3 \mathrm{t} \mathrm{d}^{-1} \mathrm{CO}_{2}$ release

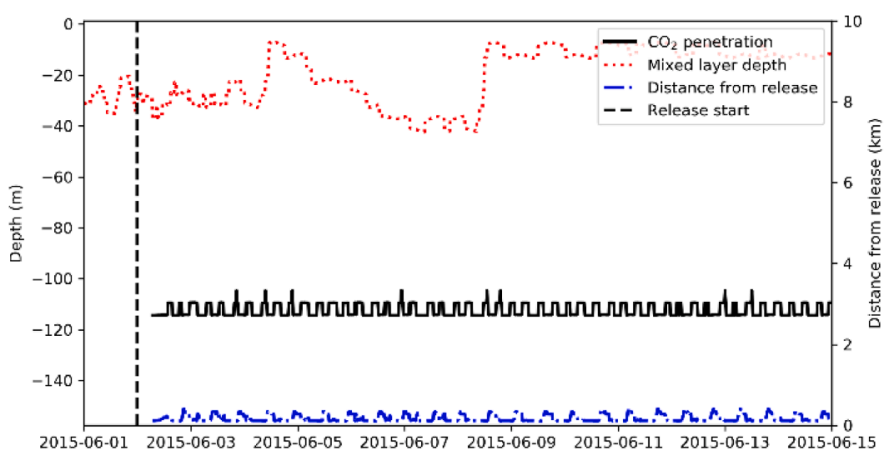

(d) $30 \mathrm{td}^{-1} \mathrm{CO}_{2}$ release

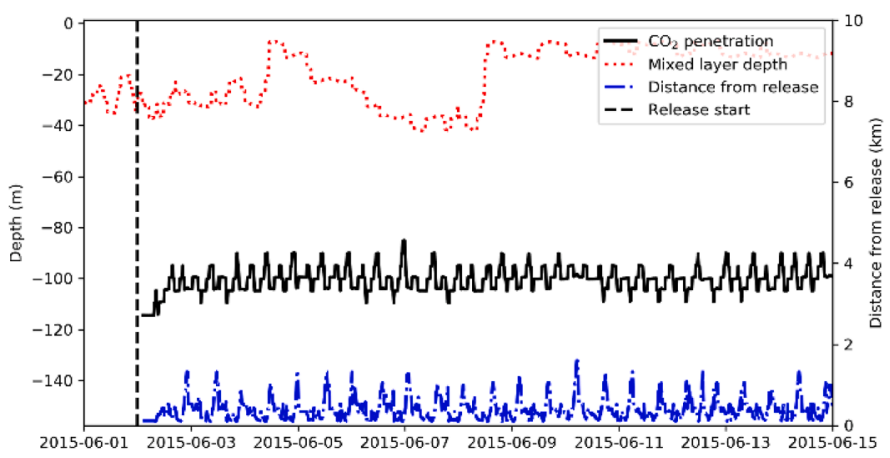

(f) $300 \mathrm{td}^{-1} \mathrm{CO}_{2}$ release

Figure 6. Time series of the minimum depth at any point in the model domain where a drop of $0.01 \mathrm{in} \mathrm{pH}$ was experienced for the release scenarios in table1. Left column (a, c, and e) shows the results for winter (fully mixed) and the right column (b, d, and f) the results from summer (stratified). The red dotted line indicates the mixed layer depth at the location at which the threshold was exceeded; gaps in the line indicate the water column is fully mixed. The dashed vertical line indicates the start of the release. The blue dashed line indicates the distance from the release at which the threshold $\mathrm{pH}$ change was located.

morphology can be split into two regimes. The first and most common one is an elongated plume whose long axis follows the tidal axis (figures $7 \mathrm{a}$ and $7 \mathrm{~b}$ ), stretching up to $10 \mathrm{~km}$ from the release location. The other aspect of the regime is illustrated by figures $7 \mathrm{c}$ and $7 \mathrm{~d}$, which show the plume as the tide turns (when the velocities approach zero and the tide flows in the reverse direction). During this second regime, the plume can be seen to curve around, at times interacting with the ongoing $\mathrm{CO} 2$ release, before settling into a shape governed by the tidal flow axis. Spatial distributions of the $\mathrm{CO} 2$ concentrations differ only at slack tide (e.g. figure $7 \mathrm{a}$, when the plume tail concentration is lower. The plume $\mathrm{CO} 2$ concentration is also characterised by a higher $\mathrm{CO} 2$ concentration and corresponding increase in change in $\mathrm{pH}$ height above the bed (e.g. figure $6 \mathrm{e}$ ) as $\mathrm{CO} 2$ is allowed to accumulate at the release location due to the low current speeds.

From a sampling perspective, the behaviour of the plume is principally controlled by the tidal axis: sensors which sample the seabed along the tidal axis relative to the release location will have a greater chance of seeing a detectable change in $\mathrm{pH}$ than those which are placed orthogonal to the tidal axis. A pH sensor placed along the tidal axis relative to the release will see an extended period of lower $\mathrm{pH}$ (as it sits in the plume) followed by a period of background $\mathrm{pH}$ before again seeing lowered $\mathrm{pH}$ as the tide turns. The $\mathrm{pH}$ of the water column for the duration of the slack tide will generally decrease as the $\mathrm{CO} 2$ is concentrated in the vicinity of the release due to the absence of any tidal currents. As the tidal velocities increase, however, this lower $\mathrm{pH}$ water will be advected by the tide and nearby sensors will see a corresponding drop in $\mathrm{pH}$.

\subsection{Monitoring Network Analysis}

Figure 8 shows the results of the optimal sampling algorithm when applied to the model layer above the seabed under stratified conditions, with increasing release rates $(3 \mathrm{t} \mathrm{d}-1,30 \mathrm{t} \mathrm{d}-1$, and $300 \mathrm{td}-1)$. The spatial coverage of each optimised sampling decreases with increasing release rate: $393 \mathrm{~km} 2,353 \mathrm{~km} 2$, and $266 \mathrm{~km} 2$ for releases of $3 \mathrm{t} \mathrm{d}-1,30$ $\mathrm{t} \mathrm{d}-1$, and $300 \mathrm{td}-1$. This coverage trend can be explained by the higher gradients seen at higher release rates, which means the 


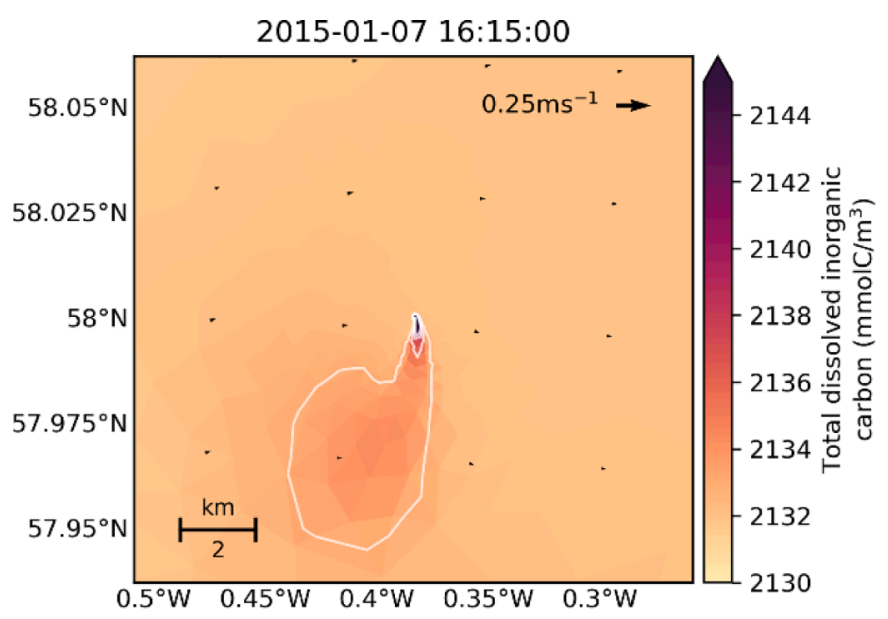

(a) $\mathrm{CO}_{2}$ plume at slack tide following southward flow

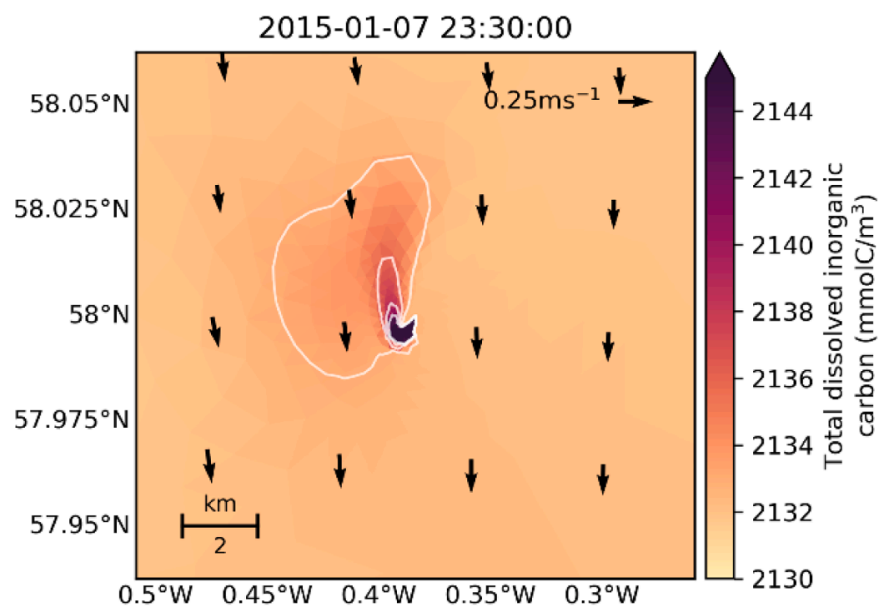

(c) $\mathrm{CO}_{2}$ plume near slack tide following northward flow

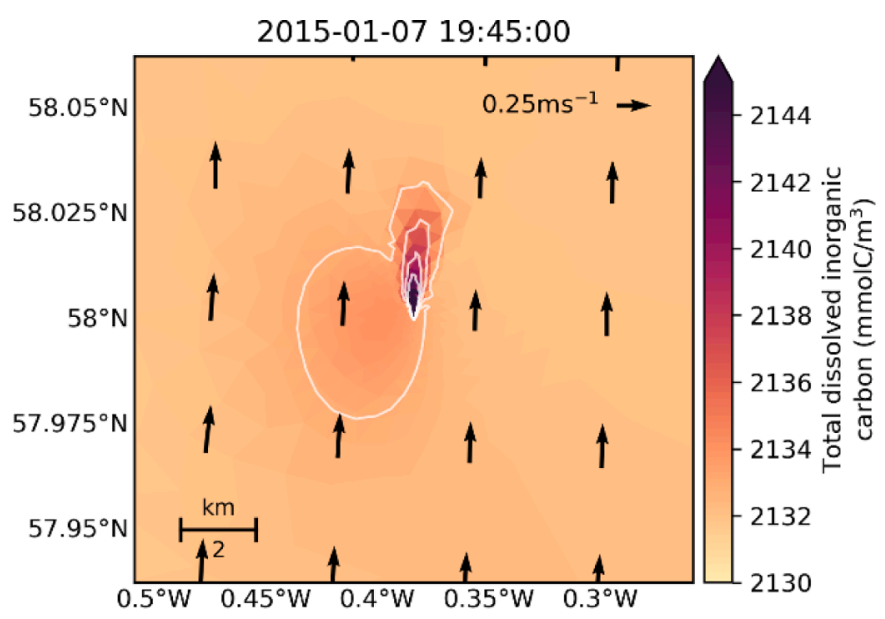

(b) $\mathrm{CO}_{2}$ plume during northward flow

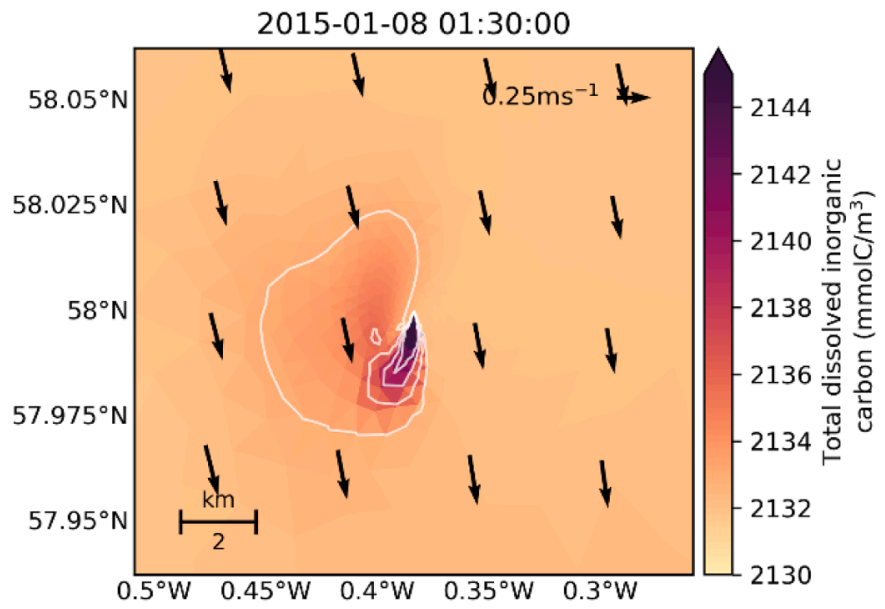

(d) $\mathrm{CO}_{2}$ plume during southward flow

Figure 7. Seabed plume dynamics in the vicinity of a $300 \mathrm{td}-1 \mathrm{CO} 2$ release. Black arrows indicate the current magnitude and direction at the time of the snapshot. Contours are at intervals of $3 \mathrm{mmolC} / \mathrm{m} 3$.

correlation coefficient threshold is breached after a smaller number of nodes due to the greater heterogeneity of the water column in the region of each sample location (figure 3a). This greater variability in $\mathrm{CO} 2$ distributions means the combined size of each region is smaller for the same number of monitoring stations.

The distribution of the identified optimal sampling points (coloured circles in figure 8) within the Golden- eye complex (black box in figure 8) is split into two distributions: for release rates of $3 \mathrm{td}-1$ and $30 \mathrm{t} \mathrm{d}-1$, the network extends further to the west and east; for the higher release rate $(300 \mathrm{td}-1)$, recommended monitoring locations tend to the south and west, due to differences in the transport of $\mathrm{CO} 2$ at low and high release rates. However, the differences between the two sets of results are of a single monitoring station. Thus, for real-world applications, the aggregate of all the positions (figure 8e) gives an optimal sampling network for release rates of between $3 \mathrm{t} \mathrm{d}-1$ to $300 \mathrm{td}-1$.

At low release rates (figures 5 a to $5 \mathrm{~d}$ ), the tidal currents do not transport the $\mathrm{CO} 2$ very far from the release site before diluting down to near background values, meaning the weighting applied is less relevant as most of the $\mathrm{CO} 2$ stays close to the release site relative to the initial grid spacing (figure $3 \mathrm{a}$ ). In contrast, at higher release rates (figures $5 \mathrm{~g}$ to $5 \mathrm{~h}$ ), the $\mathrm{CO} 2$ is transported further from the release site meaning the coverage of each point in the set is more variable which in turn yields an optimal set which includes a different group of sampling sites.

Given the tidal stream information (section 3.1), the distribution of the sampling sites with different release rates (figure 8) indicates that the local tidal conditions must be understood before deploying instrumentation.

\subsection{Sampling Validation}

Complex methods for identifying optimal sampling must be compared against simpler sampling schemes. It is easy to fall into the trap that because something is complex it is necessarily better, but given the potential real costs associated with monitoring, validation against simpler schemes must be considered.

To validate the method outlined above, the same number of sampling stations as used in the weighted greedy set approach are evenly distributed within the Goldeneye complex (figure 9). Figure 10 shows the time series of the difference in $\mathrm{pH}$ between a no release run and the 3,30 , and $300 \mathrm{td}-1$ releases. The data are extracted at the regular and weighted greedy set positions from the model layer above the seabed during fully mixed conditions.

Based on the first recorded deviation in $\Delta \mathrm{pH}$ from zero, the regular sampling network first encounters the released $\mathrm{CO} 27$ hours after the weighted greedy set network does. Since the rate at which the release makes its way to the sea surface and into the atmosphere is faster in winter than summer (due to stratification impeding transfer of $\mathrm{CO} 2$ to the upper water column), this represents a lower bound on the 


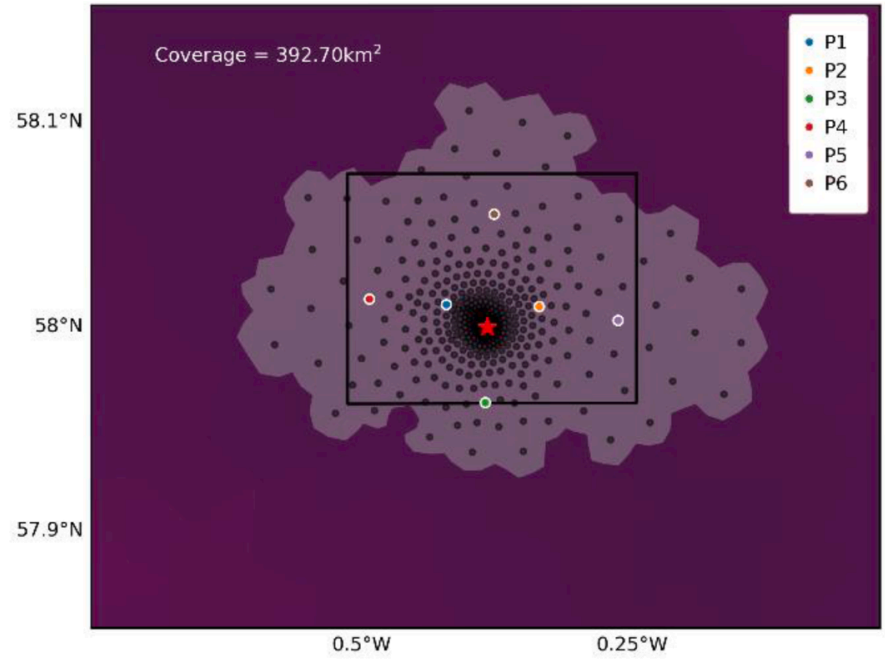

(a) Monitoring network and coverage for a $3 \mathrm{t} \mathrm{d}^{-1}$ release

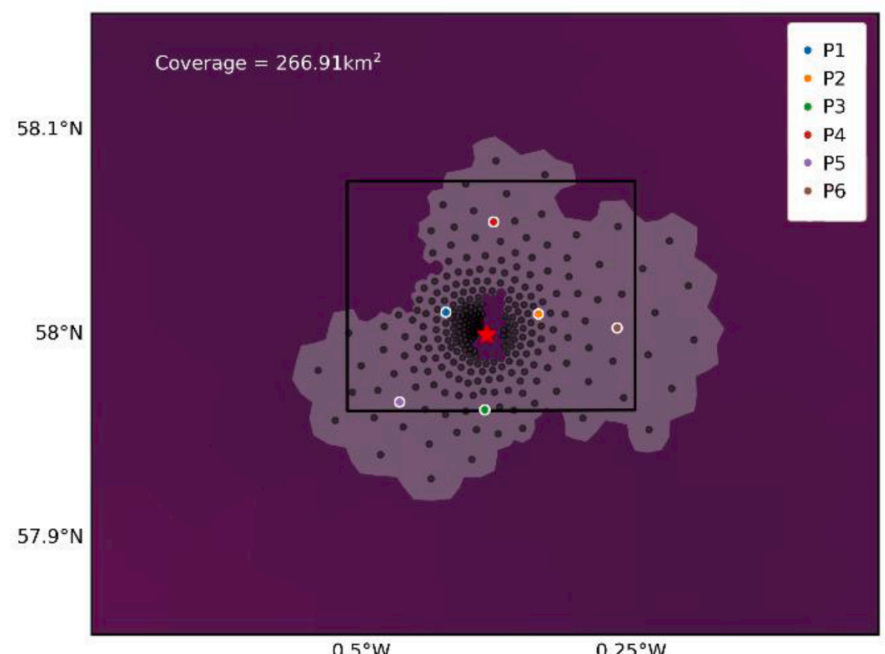

(c) Monitoring network and coverage for a $300 \mathrm{t} \mathrm{d}^{-1}$ release

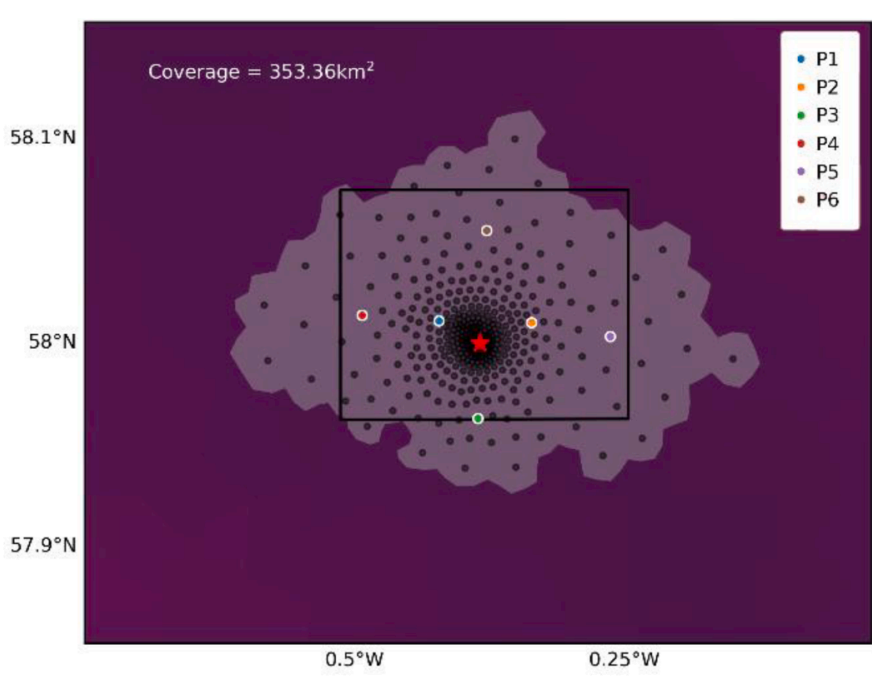

(b) Monitoring network and coverage for a $30 \mathrm{t} \mathrm{d}^{-1}$ release

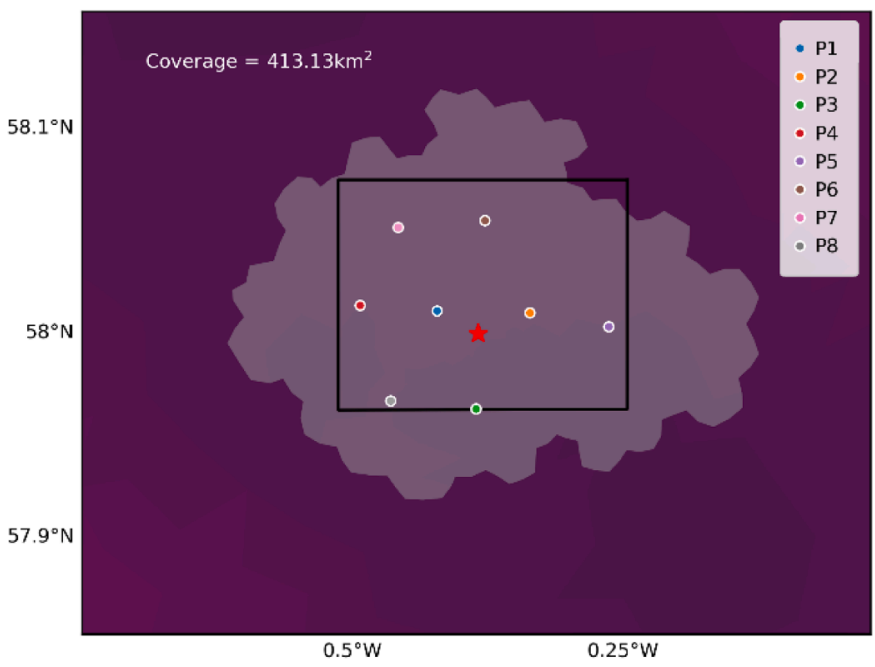

(d) Optimal monitoring network and coverage for release rates between $3 \mathrm{t} \mathrm{d}^{-1}$ and $300 \mathrm{t} \mathrm{d}^{-1}$ from the combination of locations in figures $8 \mathrm{a}-8 \mathrm{c}$.

Figure 8. The results of the weighted greedy set algorithm analysis for designing a monitoring network for a stratified water column with the release scenarios in table1. Point colours for $8 \mathrm{a}-8 \mathrm{c}$ refer to the lines in figure $10 \mathrm{a}$.

improvement in detection from the method for sampling the water column outlined here. The corresponding test on model results from the stratified water column shows that the difference in release detection increases to 17 hours.

In addition to the simple timing improvements, the weighted greedy set sampling algorithm also identifies signals with a greater magnitude: $\mathrm{pH}$ changes relative to the no release scenario are detected with an average of twice that for the regular sampling in each scenario. Since larger changes are easier to detect with in situ sensors, this is a significant improvement. An important aspect of the results of the detection is that for the $30 \mathrm{td}-1$ release, the variability in $\Delta \mathrm{pH}$ at the sites selected by both the weighted greedy set and simpler scheme are well below the levels which can be reliably discerned by current $\mathrm{pH}$ sensors (typically of order 0.01 reliably and 0.001 under certain circumstances).

\section{Discussion}

Effective monitoring of CCS is required to ensure the integrity of the reservoir and thus the long- term $\mathrm{CO} 2$ storage. The identification of potential release pathways from geological storage and the estimation of the likelihood these will become active is a requirement of EU directive 2009/31/EC for CCS site characterisation (European Union, 2011). Monitoring must include geological (both consolidated and unconsolidated sediments) and water column monitoring. A range of methods for monitoring the water column have been proposed, including acoustic and geochemical (Blackford et al., 2015; Korre et al., 2011; Shitashima et al., 2015). Monitoring water column chemistry is part of the suite of tools which will need to be put in place. Developing optimal monitoring strategies has implications ranging from the cost of monitoring to the likelihood of spotting a release in a timely manner. The definition of optimal in the context of CCS is to balance the number of sampling stations and the associated cost with the probability of identifying a release.

The modelling and accompanying analysis of the results presented here shows how a range of $\mathrm{CO} 2$ release rates from a point source in a tidally driven shelf sea propagate under fully mixed and stratified conditions. These results are used to identify the area and volume of water affected for specific changes in $\mathrm{pH}$. The modelling shows that release rates of up to $30 \mathrm{td}-1$ do not induce changes in $\mathrm{pH}$ of greater than 0.01 in this model setup. In addition to potential changes from a $\mathrm{CO} 2$ release, 


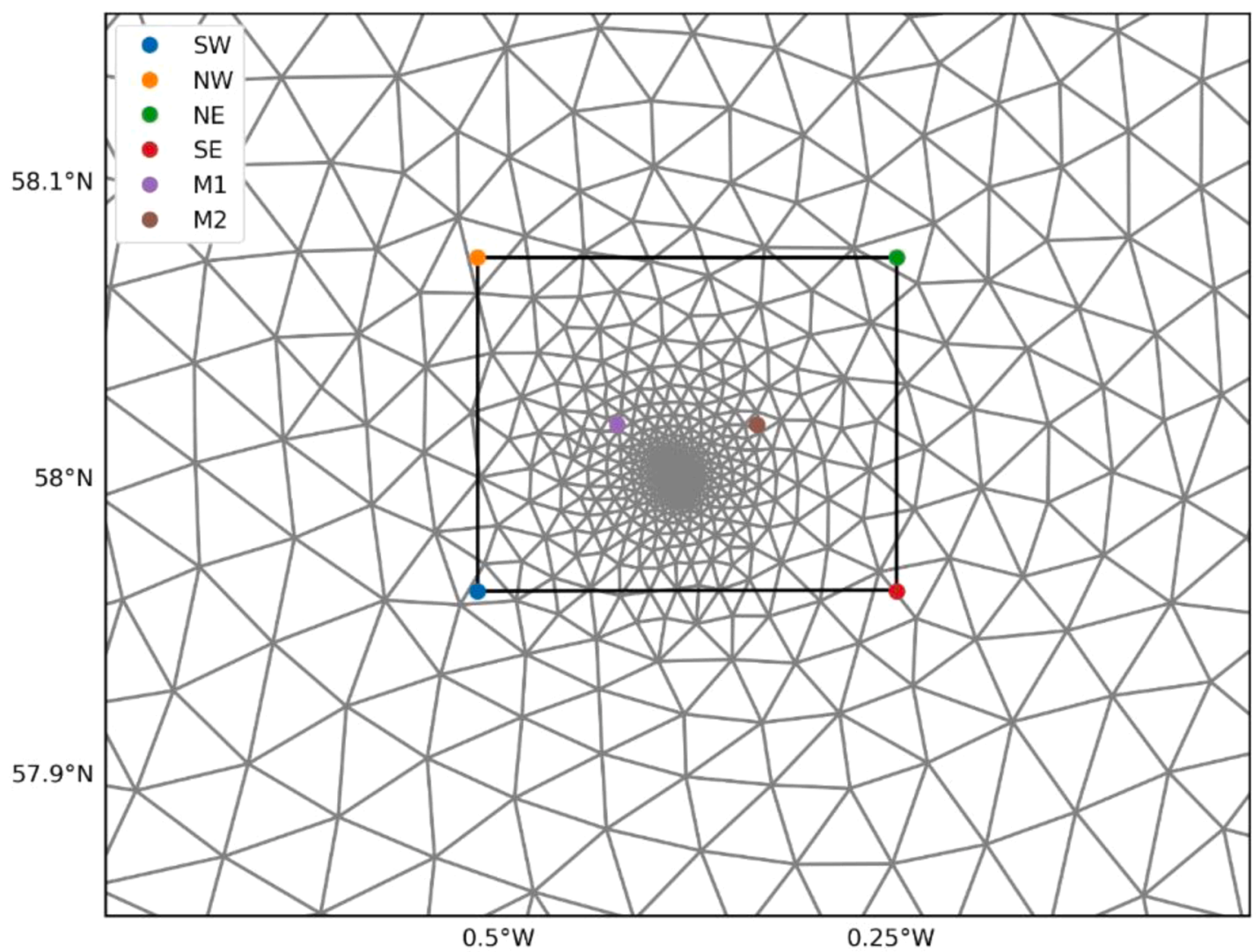

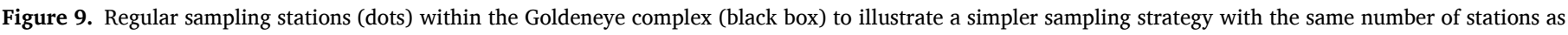
the optimised approach (figure 8). Colours match those in the time series validation plot in figure 10.

changes in the carbonate system seen in existing models and observations show that there is significant seasonal and interannual variability, driven primarily by biological processes which can be used to determine temporally varying thresholds for $\mathrm{CO} 2$ release detection (Blackford et al., 2017). The inter-annual variability of physical conditions would influence flow dynamics over time, which could impact on the plume distribution and chemical changes. The simulations were re-run using forcing data (described in section 2.1.2.) from the following year, 2016, with no significant differences seen in the maximum values for the affected plume areas, volumes and lengths over both the summer and winter periods, showing the model is representative of average contemporary current conditions. However macro changes in regional dynamics, perhaps reflecting different phases in basin scale oscillations may imply that monitoring strategies would need periodic modification.

The morphology of the plume is principally controlled by the tides. Local changes in $\mathrm{pH}$ are modulated by the tide, with larger drops at slack water. The length of the plume is a function of the release rate, with plume extending up to $77 \mathrm{~m}$ for a $3 \mathrm{t} \mathrm{d}-1$ release and up to $420 \mathrm{~km}$ for $3000 \mathrm{t} \mathrm{d}-1$ releases, accounting for model resolution, this gives a reasonable fitting to the detection length function $\mathrm{L}=60 \times \mathrm{R}^{\wedge} 0.704$ given by Blackford et al. (2020), where $\mathrm{R}$ is the release rate ( $\mathrm{t} \mathrm{d}-1$ ) and $\mathrm{L}$ is the detection length (m). Horizontal effects from the release of $\mathrm{CO} 2$ into the water column are confined to within $15 \mathrm{~km} 2$ for all tested release rates for a drop in $\mathrm{pH}$ of 0.01 . The vertical transport of $\mathrm{CO} 2$ from the release at the seabed into the water column is strongly controlled by the surface mixing. For the summer scenarios, the maximum vertical extent of the change due to the $\mathrm{CO} 2$ release for a 0.01 drop in $\mathrm{pH}$ is constant and maintained in the mid to lower water column after the initial upward transport for all release rates; in contrast, when the water column is fully mixed, the released $\mathrm{CO} 2$ frequently approaches the surface for all rates except the lowest ( $3 \mathrm{td}-1$ ). In both mixed and stratified conditions, the effect of mixing due to the tides serves to lower the height above the seabed at which the threshold $\mathrm{pH}$ value is breached. Thus, monitoring methods for released $\mathrm{CO} 2$ (via changes in $\mathrm{pH}$, for example) are more likely to identify a leak in a timely fashion if they are at the seabed rather than at the sea surface (e.g. a buoy).

The weighted greedy set algorithm presented here can design monitoring networks for tracers released from point sources in tidally driven coastal seas. The algorithm is implemented to show how a monitoring network can be designed which improves release detection timelines. This approach expands on the methods in She et al. (2014) by adopting the use of a set-based analysis rather than an approach based on the explained variance of time series.

The weighted greedy set algorithm has been applied to a range of potential release rates and used to design an optimal sampling strategy for an exemplar site in the Northern North Sea (Goldeneye). Initial results of the weighted greedy set analysis yields order 50 sampling stations across the $100,000 \mathrm{~km} 2$ model domain; sampling such a large area is impractical and cost prohibitive. To mitigate this, the analysis was restricted to a more realistic number of stations (6) to determine how the coverage would be affected. Coverage decreased as the release rate increased (due to the heterogeneity of the $\mathrm{CO} 2$ in the domain) and the distribution of sampling stations was biased based on the tidal axis, favouring locations west of the release in line which matches the tidal axis $\left(20^{\circ}\right.$ to $\left.112^{\circ}\right)$. By combining the coverages from the weighted greedy set analysis for the range of release rates tested (table 1), a monitoring network was designed which is optimal across that range for the hydrodynamic conditions at the test location.

Critically, the more complex weighted greedy set algorithm approach had to be compared against a simpler strategy. By comparing the weighted greedy set sampling locations with those from a naive sampling strategy, we show that the weighted greedy set positions can both identify releases sooner and produce stronger signals in $\Delta \mathrm{pH}$, both initially and over the duration of the release. Since a stronger signal is 


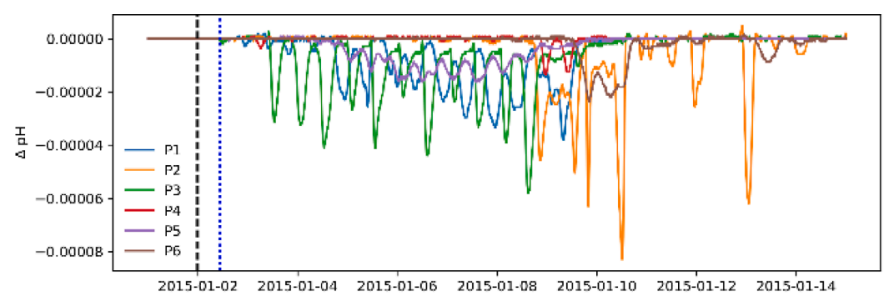

(a) Optimised sampling during a $3 \mathrm{t} \mathrm{d}^{-1}$ release.

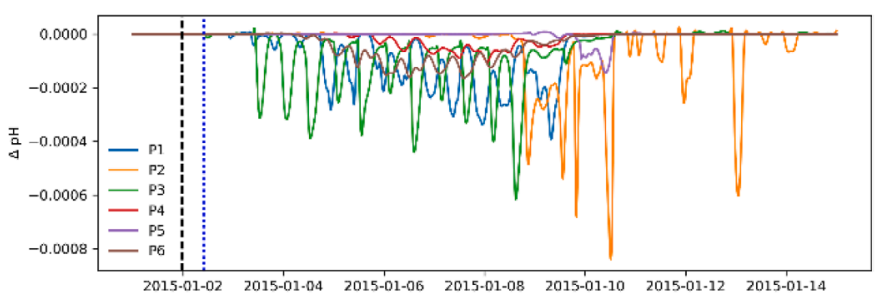

(c) Optimised sampling during a $30 \mathrm{t} \mathrm{d}^{-1}$ release.

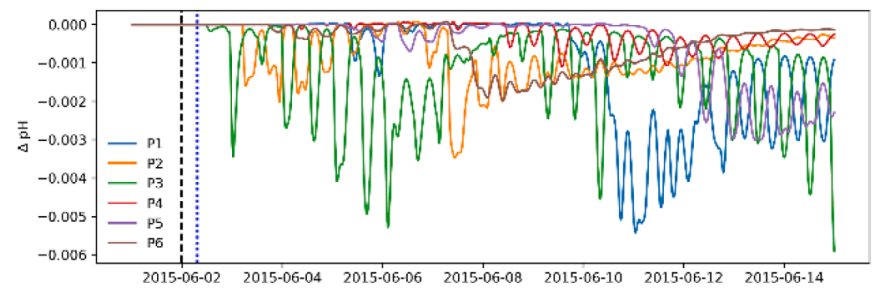

(e) Optimised sampling during a $300 \mathrm{t} \mathrm{d}^{-1}$ release.

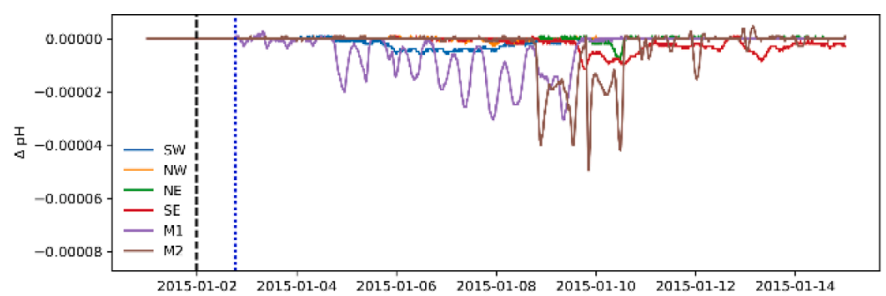

(b) Regular sampling during a $3 \mathrm{t} \mathrm{d}^{-1}$ release.

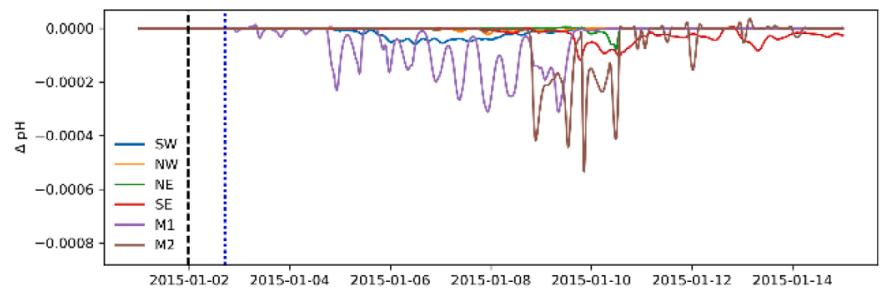

(d) Regular sampling during a $30 \mathrm{t} \mathrm{d}^{-1}$ release.

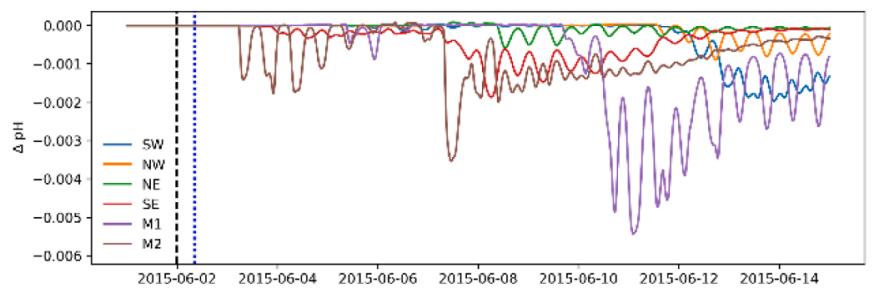

(f) Optimised sampling during a $300 \mathrm{t} \mathrm{d}^{-1}$ release.

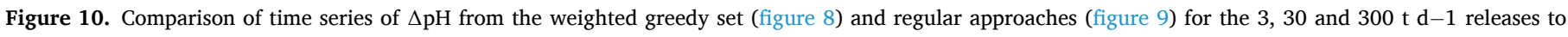

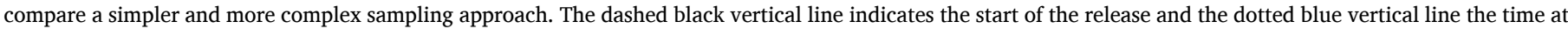

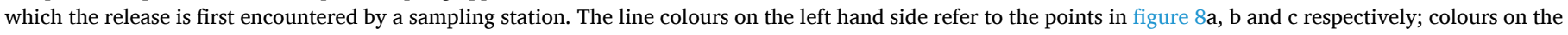
right hand side refer to those in figure 9.

more easily distinguished from a background signal, this significantly increases the chances of both identifying a release and doing so correctly. Previous work (Blackford et al., 2017) has shown that the sensitivity of changes in $\mathrm{pH}$ is strongly correlated with the likelihood of a true positive release identification, so optimising the sampling locations to maximise the potential changes in $\mathrm{pH}$ increases the chances of correctly identifying a release.

\section{Conclusions}

Without Carbon Capture and Storage (CCS), international targets for minimising increases in global temperature are very unlikely to be met. For marine CCS to become a widely deployed climate change mitigation technique, it is critical that adequate and effective monitoring is in place. The work presented here combines numerical modelling of ocean physics with the carbonate chemistry of $\mathrm{CO} 2$ in marine environments to develop optimal monitoring networks whose design is based on a weighted greedy set algorithm.

The distance $\mathrm{CO} 2$ is transported from the release location is primarily governed by the tides in the region. Both tidal mixing and surface insolation (and the subsequent seasonal stratification that occurs) play an important role in the propagation of the $\mathrm{CO} 2$ upwards in the water column. The variability in water column properties from spring and neap tides, as well as from fully mixed to stratified conditions, both play an important role in the distribution of the $\mathrm{CO} 2$ plume from its source. Site selection must, therefore, carefully consider hydrodynamic conditions in the vicinity of the storage complex. Furthermore, the potential changes due to anticipated global climate change must be factored in as a site may be suitable today but may, over time, become less suitable (due to changes in stratification and/or tidal currents).

Changes in $\mathrm{pH}$ in the vicinity of the release are temporally variable despite constant input, with larger drops associated with slack tides as $\mathrm{CO} 2$ accumulates under low velocity conditions. In terms of anticipated sensor placements, this shows that there will be significant variability at the sensors as the tides advect the water column. These findings can help facilitate the planning of anticipated impacts and determine the number of in situ sensors which might be required for a given potential release rate.

For realistic required coverages and sensor numbers, when the weighted greedy set analysis is limited to 6 sensors for each release rate, the optimal placement of sensors is principally governed by both the release rate and the tidal conditions. Combining the optimal networks for each release rate increases the required number of sensors from 6 to 8 and provides a network design which is optimal for release rates across four orders of magnitude. Comparison of the simple monitoring design with the weighted greedy set network shows that the latter is found to identify the modelled release 7 hours earlier and with $\Delta \mathrm{pH}$ values four times larger.

Whilst the use of a weighted greedy set for designing optimal monitoring networks has been applied here in the context of CCS, the technique is more widely applicable. For example, developing in situ monitoring networks for sea surface chlorophyll for remote sensing match up validation could combine existing remote sensing imagery and/or numerical modelling output with the weighted greedy set approach.

This paper shows that using a weighted greedy set algorithm to design optimal sensor networks, the likelihood of early detection, and hence the assurance of no-leakage, can be increased significantly whilst minimising the numbers of sensors used. 


\section{CRediT authorship contribution statement}

Pierre William Cazenave: Conceptualization, Methodology, Software, Validation, Formal analysis, Investigation, Data curation, Writing - original draft, Visualization. Marius Dewar: Validation, Formal analysis, Investigation, Writing - review \& editing. Ricardo Torres: Methodology, Software. Jerry Blackford: Conceptualization, Methodology, Software, Resources, Data curation, Supervision, Project administration, Funding acquisition. Michael Bedington: Methodology, Software. Yuri Artioli: Methodology, Software. Jorn Bruggeman: Methodology, Software.

\section{Declaration of Competing Interest}

The authors declare that they have no known competing financial interests or personal relationships that could have appeared to influence the work reported in this paper.

The authors declare the following financial interests/personal relationships which may be considered as potential competing interests:

\section{Acknowledgements}

The authors were supported by the European Union's Horizon 2020 research and innovation programme under grant agreement No.654462 (STEMM-CCS) and the UK Research and Innovation National Environmental Research Council (UKRI-NERC) National Capability funding program CLASS (NE/R015953/1). This work is also part of the project ACTOM, funded through the ACT programme (Accelerating CCS Technologies, Horizon 2020 Project No 294766). Financial contributions made from; The Research Council of Norway, (RCN), Norway, Netherlands Enterprise Agency (RVO), Netherlands, Department for Business, Energy \& Industrial Strategy (BEIS) together with extra funding from NERC and EPSRC research councils, United Kingdom, USDepartment of Energy (US-DOE), USA. In-kind contributions from the University of Bergen are gratefully acknowledged. The authors also acknowledge the Research Council of Norway through the CLIMIT program funded project no 254711 (Baymode).

The $1 / 15 \times 1 / 10^{\circ}$ north-west European continental shelf operational FOAM outputs were obtained from CMEMS (http://marine.cope rnicus.eu). Generation of model inputs for FVCOM used the FVCOM MATLAB toolbox (Cazenave et al., 2019). Analysis and production of plots leveraged the following tools: PyFVCOM (Cazenave, et al., 2019); SciPy (Jones et al., 2001); NumPy (Van Der Walt et al., 2011); Shapely (Gillies, 2007); IPython (Perez and Granger, 2007); Matplotlib (Hunter, 2007); GNU Parallel (Tange, 2011). Colour maps used are those from the Matplotlib cmocean package by Kristen Thyng.

\section{References}

Adams, T., Black, K., MacIntyre, C., MacIntyre, I., Dean, R., 2012. Connectivity modelling and network analysis of sea lice infection in Loch Fyne. west coast of Scotland. Aquac. Environ. Interact. 3, 51-63. https://doi.org/10.3354/aei00052.

Adams, T.P., Miller, R.G., Aleynik, D., Burrows, M.T., 2014. Offshore marine renewable energy devices as stepping stones across biogeographical boundaries. J. Appl. Ecol. 51, 330-338. https://doi.org/10.1111/1365-2664.12207.

Aleynik, D., Dale, A.C., Porter, M., Davidson, K., 2016. A high resolution hydrodynamic model system suitable for novel harmful algal bloom modelling in areas of complex coastline and topography. Harmful Algae, Applied Simulations and Integrated Modelling for the Understanding of Toxic and Harmful Algal Blooms (ASIMUTH) 53, 102-117. 10.1016/j.hal.2015.11.012.

Artioli, Y., Blackford, J.C., Butenschön, M., Holt, J.T., Wakelin, S.L., Thomas, H., Borges, A.V., Allen, J.I., 2012. The carbonate system in the North Sea: Sensitivity and model validation. J. Mar. Syst 102-104, 1-13. https://doi.org/10.1016/j. jmarsys.2012.04.006.

Artioli, Y., Blackford, J.C., Nondal, G., Bellerby, R.G.J., Wakelin, S.L., Holt, J.T., Butenschön, M., Allen, J.I., 2014. Heterogeneity of impacts of high CO2 on the North Western European Shelf. Biogeosciences 11, 601-612. https://doi.org/10.5194/bg11-601-2014.

Barange, M., Allen, I., Allison, E., Badjeck, M.-C., Blanchard, J., Drakeford, B., Dulvy, N. K., Harle, J., Holmes, R., Holt, J., Jennings, S., Lowe, J., Merino, G., Mullon, C., Pilling, G., Rodwell, L., Tompkins, E., Werner, F., 2011. Predicting the Impacts and
Socio-Economic Consequences of Climate Change on Global Marine Ecosystems and Fisheries, in: World Fisheries. John Wiley \& Sons 29-59. https://doi.org/10.1002/ 9781444392241.ch3.

7 Behavior and dynamics of bubble breakup in gas pipeline leaks and accidental subsea oil well blowouts. Mar. Pollut. Bull. 131, 2018, 72-86. https://doi.org/10.1016/j. marpolbul.2018.03.053.

Blackford, J., Alendal, G., Avlesen, H., Brereton, A., Cazenave, P.W., Chen, B., Dewar, M., Holt, J., Phelps, J., 2020. Impact and detectability of hypothetical CCS offshore seep scenarios as an aid to storage assurance and risk assessment. Int. J. Greenh. Gas Control 95, 102949. https://doi.org/10.1016/j.ijggc.2019.102949.

Blackford, J., Artioli, Y., Clark, J., de Mora, L., 2017. Monitoring of offshore geological carbon storage integrity: Implications of natural variability in the marine system and the assessment of anomaly detection criteria. Int. J. Greenh. Gas Control 64, 99-112. https://doi.org/10.1016/j.ijggc.2017.06.020.

Blackford, J., Bull, J.M., Cevatoglu, M., Connelly, D., Hauton, C., James, R.H., Lichtschlag, A., Stahl, H., Widdicombe, S., Wright, I.C., 2015. Marine baseline and monitoring strategies for carbon dioxide capture and storage (CCS). Int. J. Greenh. Gas Control. CCS and the Marine Environment 38, 221-229. https://doi.org/ 10.1016/j.ijggc.2014.10.004.

Blackford, J.C., Allen, J.I., Gilbert, F.J., 2004. Ecosystem dynamics at six contrasting sites: a generic modelling study. J. Mar. Syst. 52, 191-215. https://doi.org/10.1016/ j.jmarsys.2004.02.004.

Blackford, J.C., Burkill, P.H., 2002. Planktonic community structure and carbon cycling in the Arabian Sea as a result of monsoonal forcing: the application of a generic model. J. Mar. Syst. 36, 239-267. https://doi.org/10.1016/S0924-7963(02)001823 .

Blackford, J.C., Gilbert, F.J., 2007. pH variability and CO2 induced acidification in the North Sea. J. Mar. Syst., Contributions from Advances in Marine Ecosystem Modelling Research, 27-29 June, 2005. Plymouth, UKAMEMR 64, 229-241. https:// doi.org/10.1016/j.jmarsys.2006.03.016.

Blackford, J.C., Jones, N., Proctor, R., Holt, J., 2008. Regional scale impacts of distinct CO2 additions in the North Sea. Mar. Pollut. Bull. 56, 1461-1468. https://doi.org/ 10.1016/j.marpolbul.2008.04.048.

Blackford, J.C., Torres, R., Cazanave, P., Artioli, Y., 2013. Modelling Dispersion of CO2 Plumes in Sea Water as an Aid to Monitoring and Understanding Ecological Impact. Energy Procedia 37, 3379-3386. https://doi.org/10.1016/j. egypro.2013.06.226Blomquist. GHGT-11.

Brumer, B.W., Fairall, S.E., Huebert, C.W., Zappa, B.J., Brooks, C.J., Yang, I.M., Bariteau, M., Prytherch, L., Hare, J., Czerski, J.E., Matei, H., Pascal, A., 2017. Wind Speed and Sea State Dependencies of Air-Sea Gas Transfer: Results From the High Wind Speed Gas Exchange Study (HiWinGS). J. Geophys. Res. Oceans 122, 8034-8062. https://doi.org/10.1002/2017JC013181.

Blomquist, B.W., Brumer, S.E., Fairall, C.W., Huebert, B.J., Zappa, C.J., Brooks, I.M., Yang, M., Bariteau, L., Prytherch, J., Hare, J.E., Czerski, H., Matei, A., Pascal, R.W., 2017. Wind Speed and Sea State Dependencies of Air-Sea Gas Transfer: Results From the High Wind Speed Gas Exchange Study (HiWinGS). J. Geophys. Res. Oceans 122, 8034-8062. https://doi.org/10.1002/2017JC013181.

Bruggeman, J., Bolding, K., 2014. A general framework for aquatic biogeochemical models. Environ. Model. Softw. 61, 249-265. https://doi.org/10.1016/j. envsoft.2014.04.002.

Butenschön, M., Clark, J., Aldridge, J.N., Icarus Allen, J., Artioli, Y., Blackford, J. Bruggeman, J., Cazenave, P., Ciavatta, S., Kay, S., Lessin, G., van Leeuwen, S., van der Molen, J., de Mora, L., Polimene, L., Sailley, S., Stephens, N., Torres, R., 2016. ERSEM 15.06: a generic model for marine biogeochemistry and the ecosystem dynamics of the lower trophic levels. Geosci. Model Dev. 9, 1293-1339. 10.51 94/gmd-9-1293-2016.

Cazenave, P., Bedington, M., Torres, R., 2019 a. pwcazenave/PyFVCOM 2.2.0. Zenodo. 10.5281/zenodo.2671617.

Cazenave, P., Torres, R., O'Hara Murray, R., Amoudry, K., Liu, C., 2019. pwcazenave/ fvcom-toolbox: Relatively minor fixes with improvements and bug squashing. Zenodo. https://doi.org/10.5281/zenodo.2573959.

Cazenave, P.W., Torres, R., Allen, J.I., 2016. Unstructured grid modelling of offshore wind farm impacts on seasonally stratified shelf seas. Prog. Oceanogr. 145, 25-41. https://doi.org/10.1016/j.pocean.2016.04.004.

Chao, Y., Li, Z., Farrara, J.D., Hung, P., 2009. Blending Sea Surface Temperatures from Multiple Satellites and In Situ Observations for Coastal Oceans. J. Atmospheric Ocean. Technol. 26, 1415-1426. https://doi.org/10.1175/2009JTECHO592.1.

Chen, 2013. An Unstructured-grid, Finite-volume Community Ocean Model: FVCOM User Manual, 3rd Edition. Sea Grant College Program, Massachusetts Institute of Technology.

Chen, B., Song, Y., Nishio, M., Someya, S., Akai, M., 2005. Modeling near-field dispersion from direct injection of carbon dioxide into the ocean. J. Geophys. Res. Oceans 110, C09S15. https://doi.org/10.1029/2004JC002567.

Chen, C., Huang, H., Beardsley, R.C., Liu, H., Xu, Q., Cowles, G., 2007. A finite volume numerical approach for coastal ocean circulation studies: Comparisons with finite difference models. J. Geophys. Res. 112 https://doi.org/10.1029/2006JC003485.

Chen, C., Liu, H., Beardsley, R.C., 2003. An Unstructured Grid, Finite-Volume, ThreeDimensional, Primitive Equations Ocean Model: Application to Coastal Ocean and Estuaries. J. Atmospheric Ocean. Technol. 20, 159-186, 10.1175/1520-0426(2003) $020<0159$ :AUGFVT> 2.0.CO;2.

Dasanayaka, L.K., Yapa, P.D., 2009. Role of plume dynamics phase in a deepwater oil and gas release model. J. Hydro-Environ. Res. 2, 243-253. https://doi.org/10.1016/j.jh er.2009.01.004.

De Dominicis, M., O'Hara Murray, R., Wolf, J., 2017. Multi-scale ocean response to a large tidal stream turbine array. Renew. Energy 114, 1160-1179. https://doi.org/ 10.1016/j.renene.2017.07.058. 
Dewar, M., Sellami, N., Chen, B., 2015. Dynamics of rising CO2 bubble plumes in the QICS field experiment: Part 2 - Modelling. Int. J. Greenh. Gas Control, CCS and the Marine Environment 38, 52-63. https://doi.org/10.1016/j.ijggc.2014.11.003.

Dewar, M., Wei, W., McNeil, D., Chen, B., 2013. Small-scale modelling of the physiochemical impacts of $\mathrm{CO} 2$ leaked from sub-seabed reservoirs or pipelines within the North Sea and surrounding waters. Mar. Pollut. Bull., Ecological impacts of CCS leakage 73, 504-515. https://doi.org/10.1016/j.marpolbul.2013.03.005.

Dewar, M., Wei, W., McNeil, D., Chen, B., 2013b. Simulation of the Near Field Physiochemical Impact of CO2 Leakage into Shallow Water in the North Sea. Energy Procedia, GHGT-11 37, 3413-3423. 10.1016/j.egypro.2013.06.230.

European Union, P.O. of the E., 2011. Implementation of directive 2009/31/EC on the geological storage of carbon dioxide : guidance document 3 , criteria for transfer of responsability to the competent authority. [WWW Document]. URL https://op.euro pa.eu:443/en/publication-detail/-/publication/bdb84106-a565-490a-8a34-cbf eaa53e609 (accessed 3.19.20).

Fairall, C.W., Bradley, E.F., Hare, J.E., Grachev, A.A., Edson, J.B., 2003. Bulk Parameterization of Air-Sea Fluxes: Updates and Verification for the COARE Algorithm. J. Clim. 16, 571-591, 10.1175/1520-0442(2003)016<0571: $\mathrm{BPOASF}>2.0 . \mathrm{CO} ; 2$.

Fu, W., Høyer, J.L., She, J., 2011. Assessment of the three dimensional temperature and salinity observational networks in the Baltic Sea and North Sea. Ocean Sci 7, 75-90. https://doi.org/10.5194/os-7-75-2011.

Ge, J., Ding, P., Chen, C., Hu, S., Fu, G., Wu, L., 2013. An integrated East China Sea-Changjiang Estuary model system with aim at resolving multi-scale regional-shelf-estuarine dynamics. Ocean Dyn 63, 881-900. https://doi.org/ 10.1007/s10236-013-0631-3.

Gillies, S., 2007. Toblerity/Shapely. Toblerity.

Greenwood, J., Craig, P., Hardman-Mountford, N., 2015. Coastal monitoring strategy for geochemical detection of fugitive $\mathrm{CO} 2$ seeps from the seabed. Int. J. Greenh. Gas Control 39, 74-78. https://doi.org/10.1016/j.ijggc.2015.05.010.

Huang, H., 2011. Finite Volume Coastal Ocean Model (FVCOM) 3D Hydrodynamic Model Comparison 43

Hunter, J.D., 2007. Matplotlib: A 2D Graphics Environment. Comput. Sci. Eng. 9, 90-95. https://doi.org/10.1109/MCSE.2007.55.

Hvidevold, H.K., Alendal, G., Johannessen, T., Ali, A., Mannseth, T., Avlesen, H., 2015. Layout of CCS monitoring infrastructure with highest probability of detecting a footprint of a $\mathrm{CO} 2$ leak in a varying marine environment. Int. J. Greenh. Gas Control 37, 274-279. 10.1016/j.ijggc.2015.03.013.

Ingri, N., Kakolowicz, W., Sillén, L.G., Warnqvist, B., 1967. High-speed computers as a supplement to graphical methods-V11Part IV-Arkiv Kemi, 1964, 23, 97; for commsnt on spelling "program" see Talanta, 1967, 14, 833.: Haltafall, a general program for calculating the composition of equilibrium mixtures. Talanta 14 , 1261-1286. https://doi.org/10.1016/0039-9140(67)80203-0.

Jones, E., Oliphant, T., Peterson, P., 2001. SciPy: Open Source Scientific Tools for Python.

Korre, A., Imrie, C.E., May, F., Beaubien, S.E., Vandermeijer, V., Persoglia, S., Golmen, L., Fabriol, H., Dixon, T., 2011. Quantification techniques for potential CO2 leakage from geological storage sites. Energy Procedia, 10th International Conference on Greenhouse Gas Control Technologies 4, 3413-3420. 10.1016/j.egypro.2011 .02 .265 .

Legrand, S., Deleersnijder, E., Delhez, E., Legat, V., 2007. Unstructured, anisotropic mesh generation for the Northwestern European continental shelf, the continental slope and the neighbouring ocean. Cont. Shelf Res. Recent Developments in Physical Oceanographic Modelling: Part IV 27, 1344-1356. https://doi.org/10.1016/j. csr.2007.01.009.

Legrand, S., Deleersnijder, E., Hanert, E., Legat, V., Wolanski, E., 2006. High-resolution, unstructured meshes for hydrodynamic models of the Great Barrier Reef. Australia. Estuar. Coast. Shelf Sci. 68, 36-46. https://doi.org/10.1016/j.ecss.2005.08.017.

Li, X., Li, M., Amoudry, L.O., Ramirez-Mendoza, R., Thorne, P.D., Song, Q., Zheng, P., Simmons, S.M., Jordan, L.-B., McLelland, S.J., 2020. Three-dimensional modelling of suspended sediment transport in the far wake of tidal stream turbines. Renew. Energy 151, 956-965. 10.1016/j.renene.2019.11.096.

Manceau, J.-C., Hatzignatiou, D.G., de Lary, L., Jensen, N.B., Réveillère, A., 2014. Mitigation and remediation technologies and practices in case of undesired migration of $\mathrm{CO} 2$ from a geological storage unit-Current status. Int. J. Greenh. Gas Control 22, 272-290. https://doi.org/10.1016/j.ijggc.2014.01.007.

Mellor, G.L., Yamada, T., 1982. Development of a turbulence closure model for geophysical fluid problems. Rev. Geophys. 20, 851-875. https://doi.org/10.1029/ RG020i004p00851.

Michalakes, J., Chen, S., Dudhia, J., Hart, L., Klemp, J., Middlecoff, J., Skamarock, W., 2001. DEVELOPMENT OF A NEXT-GENERATION REGIONAL WEATHER RESEARCH AND FORECAST MODEL. In: Developments in Teracomputing. Presented at the Proceedings of the Ninth ECMWF Workshop on the Use of High Performance Computing in Meteorology. WORLD SCIENTIFIC, Reading, UK, pp. 269-276. https://doi.org/10.1142/9789812799685_0024.
Nightingale, P.D., Malin, G., Law, C.S., Watson, A.J., Liss, P.S., Liddicoat, M.I., Boutin, J., Upstill-Goddard, R.C., 2000. In situ evaluation of air-sea gas exchange parameterizations using novel conservative and volatile tracers. Glob. Biogeochem. Cycles 14, 373-387. https://doi.org/10.1029/1999GB900091.

Oleynik, A., García-Ibáñez, M.I., Blaser, N., Omar, A., Alendal, G., 2020. Optimal sensors placement for detecting $\mathrm{CO} 2$ discharges from unknown locations on the seafloor. Int. J. Greenh. Gas Control 95, 102951. https://doi.org/10.1016/j.ijggc.2019.102951.

Pachauri, R.K., Allen, M.R., Barros, V.R., Broome, J., Cramer, W., Christ, R., Church, J.A., Clarke, L., Dahe, Q., Dasgupta, P., 2014. Climate change 2014: synthesis report. Contribution of Working Groups I. II and III to the fifth assessment report of the Intergovernmental Panel on Climate Change. IPCC.

Paulley, A., Metcalfe, R., Egan, M., Maul, P.R., Limer, L., Grimstad, A.-A., 2013. Hypothetical Impact Scenarios for CO2 Leakage from Storage Sites. Energy Procedia, GHGT-11 Proceedings of the 11th International Conference on Greenhouse Gas Control Technologies, 18-22 November 2012. Kyoto, Japan 37, 3495-3502. 10.101 6/j.egypro.2013.06.240.

Perez, F., Granger, B.E., 2007. IPython: A System for Interactive Scientific Computing. Comput. Sci. Eng. 9, 21-29. https://doi.org/10.1109/MCSE.2007.53.

Phelps, J.J.C., Blackford, J.C., Holt, J.T., Polton, J.A., 2015. Modelling large-scale CO2 leakages in the North Sea. Int. J. Greenh. Gas Control, CCS and the Marine Environment 38, 210-220. https://doi.org/10.1016/j.ijggc.2014.10.013.

Reynolds, R.W., 1988. A Real-Time Global Sea Surface Temperature Analysis. J. Clim. 1, 75-87, 10.1175/1520-0442(1988)001<0075:ARTGSS > 2.0.CO;2.

Sellami, N., Dewar, M., Stahl, H., Chen, B., 2015. Dynamics of rising CO2 bubble plumes in the QICS field experiment: Part 1 - The experiment. Int. J. Greenh. Gas Control, CCS and the Marine Environment 38, 44-51. https://doi.org/10.1016/j. ijggc.2015.02.011.

She, J., Allen, J.I., Arkin, S.S., Butenschön, M., Ciavatta, S., Fu, W., Kay, S., Petihakis, G., Salihoglu, C., Triantafyllou, G., Tsiaras, K., 2014. OPerational ECology: Effectiveness of routine monitoring of ecosystem properties in European regional seas. Technical Report No. 283291.

Shitashima, K., Maeda, Y., Sakamoto, A., 2015. Detection and monitoring of leaked CO2 through sediment, water column and atmosphere in a sub-seabed CCS experiment. Int. J. Greenh. Gas Control, CCS and the Marine Environment 38, 135-142. https:// doi.org/10.1016/j.ijggc.2014.12.011.

Skamarock, C., Klemp, B., Dudhia, J., Gill, O., Barker, D., Duda, G., Huang, X., Wang, W., Powers, G., 2008. A Description of the Advanced Research WRF Version 3. 10.5065/ D68S4MVH.

Smagorinsky, J., 1963. General circulation experiments with the primitive equations. Mon. Weather Rev. 91, 99-164, 10.1175/1520-0493(1963)091<0099: GCEWTP> 2.3.CO;2.

Tange, O., 2011. GNU Parallel: The Command-Line Power Tool | USENIX [WWW Document]. URL https://www.usenix.org/publications/login/february-2 011-volume-36-number-1/gnu-parallel-command-line-power-tool (accessed 3.19.20).

Torres, R., Uncles, R.J., 2011. 2.17 - Modeling of Estuarine and Coastal Waters. Treatise on Estuarine and Coastal Science 395-427. https://doi.org/10.1016/B978-0-12374711-2.00216-3.

Van Der Walt, S., Colbert, S.C., Varoquaux, G., 2011. The NumPy array: a structure for efficient numerical computation. Comput. Sci. Eng. 13, 22-30. https://doi.org/ 10.1109/MCSE.2011.37.

Waggitt, J.J., Cazenave, P.W., Howarth, L.M., Evans, P.G.H., van der Kooij, J., Hiddink, J.G., 2018. Combined measurements of prey availability explain habitat selection in foraging seabirds. Biol. Lett. 14, 20180348 https://doi.org/10.1098/ rsbl.2018.0348.

Waggitt, J.J., Cazenave, P.W., Torres, R., Williamson, B.J., Scott, B.E., 2016a. Predictable hydrodynamic conditions explain temporal variations in the density of benthic foraging seabirds in a tidal stream environment. ICES J. Mar. Sci. 73, 2677-2686. 10.1093/icesjms/fsw100.

Waggitt, J.J., Cazenave, P.W., Torres, R., Williamson, B.J., Scott, B.E., 2016b. Quantifying pursuit-diving seabirds' associations with fine-scale physical features in tidal stream environments. J. Appl. Ecol. 53, 1653-1666. https://doi.org/10.1111/ 1365-2664.12646.

Wang, B., Socolofsky, S.A., Lai, C.C.K., Adams, E.E., Boufadel, M.C., 2018. Behavior and dynamics of bubble breakup in gas pipeline leaks and accidental subsea oil well blowouts. Pollut. Bull. 131, 72-86. https://doi.org/10.1016/j.marpolbul.2018.03.0 53.

Yang, Z., Khangaonkar, T., 2008. Modeling of Salt Intrusion, Intertidal Mixing, and Circulation in a Braided Estuary. J. Coast. Res. 171-180. https://doi.org/10.2112/ 1551-5036-52.sp1.171.

Young, N.E., 2008. Greedy Set-Cover Algorithms, in: Kao, M.-Y. (Ed.), Encyclopedia of Algorithms. Springer US, Boston, MA, pp. 379-381. 10.1007/978-0-387-30162-4_ 175.

Zheng, L., Weisberg, R.H., 2012. Modeling the west Florida coastal ocean by downscaling from the deep ocean, across the continental shelf and into the estuaries. Ocean Model 48, 10-29. https://doi.org/10.1016/j.ocemod.2012.02.002. 